\title{
An Accurate Spectrophotometer for Measuring the Transmittance of Solid and Liquid Materials
}

\author{
R. Mavrodineanu
}

Analytical Chemistry Division, National Bureau of Standards, Washington, D.C. 20234

(May 31, 1972)

\begin{abstract}
The optical transmittance of solids and liquids as well as the molar absorptivity of various chemical species are parameters of fundamental significance in characterizing these materials. Meaningful transmittance data can be obtained only when the measurements are performed with well-known accuracy and precision. To perform such measurements, a high accuracy spectrophotometer was designed and assembled at NBS, Analytical Chemistry Division, and will be described in this paper. This singlebeam instrument is composed of a constant radiation source, a monochromator, a sample carriage, an integrating sphere-photomultiplier assembly followed by appropriate electronics, and a read out system consisting of a digital voltmeter and a computer data acquisition and handling provision. The accuracy of transmittance measurements is determined by the light-addition principle used in conjunction with a two-aperture arrangement. The spectrophotometer can be used in manual or automatic modes of operation. A detailed discussion of the data obtained with this instrument, used in both modes, will be presented together with its application to the certification of solid and liquid Standard Reference Materials for checking the photometric scales of conventional spectrophotometers.
\end{abstract}

Key words: Absorbance; automation of accurate spectrophotometer; instrumentation, spectrophotometric; spectrophotometry, high accuracy; standard reference material in spectrophotometry; transmittance.

\section{Introduction}

Optical transmittance is due to an intrinsic property of matter and characterizes a particular transparent material. Since this parameter is not known a priori, it must be determined by experimental procedures.

True transmittance values can be obtained only by using accurate measuring techniques and by taking into consideration all factors which can affect and distort the data. ${ }^{1}$

${ }^{1}$ The optical transmittance of a solid material includes the reflection losses which occur

at the air-solid interface.
The internal transmittance is defined as the transmittance of the material corrected for reflection losses (2). This internal transmittance can be calculated in principle from the transmittance by using the well known Fresnel equations (1, pp. 98 to 100$)$.

For collimated radiation the reflectance $R$, for a material with an index of refraction, $n$, and an absorptivity, $a$, at wavelength, $\lambda$, is given through:

$$
R_{\lambda}=\frac{\left(n_{\lambda}-1\right)^{2}+n_{\lambda}^{2} a_{\lambda}^{2}}{\left(n_{\lambda}+1\right)^{2}+n_{\lambda}^{2} a_{\lambda}^{2}} .
$$

For a nonabsorbing material and collimated radiation:

$$
R_{\lambda}=\frac{\left(n_{\lambda}-1\right)^{2}}{\left(n_{\lambda}+1\right)^{2}} .
$$

For glass, $n$ is approximately 1.5 in the visible region of the spectrum, and $R$ will be about 4 percent at every air-glass interface.

When noncollimated radiation is used

$$
R_{\lambda}^{\perp}=\frac{\sin ^{2}(\alpha-\beta)_{\lambda}}{\sin ^{2}(\alpha+\beta)_{\lambda}}
$$

for perpendicular polarized radiation, and

$$
R_{\lambda}^{\|}=\frac{\tan ^{2}(\alpha-\beta)_{\lambda}}{\tan ^{2}(\alpha+\beta)_{\lambda}}
$$

for parallel polarized radiation, where $\alpha$ and $\beta$ are the angles of incidence and refraction, respectively.

In collimated radiation and in air, $\alpha=\beta=0$ and $R^{\perp}=R^{\|}=R$.
Transmittance is the ratio of two radiation flux intensities. It is therefore necessary that the photometric scale of the spectrophotometer used to perform the measurements be accurate. The transmittance of a particular material is also a function of wavelength; hence the wavelength scale of the monochromator should also be accurate, and appropriate spectral bandpasses should be used. The measurements should be made using collimated radiations. Such radiations define unambiguously the actual path length through the transmitting medium, the reflection losses, and eliminate the effects of polarized radiations that are produced at the surface of the sample. Other important factors which must be considered are: homogeneity and stability of the sample, radiation scatter inside the sample, interference phenomena, stray radiation, polarization, fluorescence, temperature, particulate matter, and surface conditions. Since transmittance measurements depend on a diversity of factors, meaningful values can be obtained only by defining the experimental conditions for obtaining transmittance data $[1,2] .^{2}$ Spectrophotometers are used to perform two types of measurements:

(1) Quantitative determination of chemical species using the relation between optical transmission of the material, and the concentration as a measuring parameter. Under these circumstances, the photometric scale

\footnotetext{
${ }^{2}$ Figures in brackets indicate the literature references at the end of this paper.
} 
of the spectrophotometer is calibrated in meaningful units, using a series of reference solutions having known concentrations of the species to be determined, rather than values of optical transmittance.

The accuracy of the measurements is related solely to the accuracy with which the concentration of the reference solutions is known and to the precision (stability, sensitivity, reproducibility) of the spectrophotometric method and instrument used. The accuracy of the photometric scale per se, is not a critical factor in such measurements.

The precision, stability, and reproducibility of the instrument can be checked before each series of measurements by careful use of solid or liquid reference filters having well established transmittance values.

(2) Determination of the optical transmission characteristics of solid or liquid materials, and the determination of molar absorptivities of chemical compounds. In both cases the accuracy of the photometric scale of the measuring instrument, among other things, is essential to provide true values. Ways to establish and check this important parameter are critically needed.

Since conventional spectrophotometers do not provide means to check photometric accuracy or to evaluate the possible sources of systematic errors, it was decided in 1969 to design and construct a research spectrophotometer on which transmittance measurements could be performed with well defined accuracy. Such an instrument would be used to determine optical transmittance of selected solids and liquids at various wavelengths. These materials can be used as standard reference materials (SRM's) to check the accuracy of the photometric scale of conventional spectrophotometers. The same certified SRM's could likewise be used to monitor the precision, stability, and reproducibility of those instruments $[3,4]$.

After a comprehensive examination of the literature in this field [5 to 34] arranged in chronological order, an instrument was developed which is similar in principle to the instrument at the National Physical Laboratory (NPL), Teddington, England, where a long tradition of high accuracy spectrophotometry exists. The instrument described in this work performs. measurements of radiant energy in the visible and ultraviolet region of the spectrum, with well established and high photometric accuracy. Transmittance measurements on solids and liquids can be made with this instrument using collimated as well as noncollimated beam geometry. The wavelength accuracy and spectral bandpass achievable are adequate to avoid degradation of photometric accuracy, and the other interferences mentioned have been given careful consideration, and, in most cases, have been assessed quantitatively.

The transmittance measurements on the optically neutral glass filters discussed in this work have been made with a noncollimated beam geometry corresponding to an aperture of about $f: 10$. The image of the exit slit of the monochromator $(8 \mathrm{~mm} \times 0.5 \mathrm{~mm})$ was produced at the center of the entrance face of the filter. All measurements have been made against air for the nonattenuated radiation flux, and no correction for reflection losses was made. Transmittance measurements made with noncollimated radiation by projecting the image of the exit slit of the monochromator on the entrance face of the sample using an opening of f:10 (total angle of about $7^{\circ}$ or $8^{\circ}$ ), may differ by several parts in $10^{4}$ of the value when compared with similar measurements made with collimated radiations, as indicated in this Journal by K. Mielenz.

Noncollimated beam geometry was applied in this work to approach the measuring conditions used in most of the conventional spectrophotometers which are available today. A brief description of this instrument was given earlier in reference [3].

\section{Description of the Instrument ${ }^{3}$}

The high accuracy spectrophotometer, completed and tested in 1970, is a single beam instrument which contains the following components: (a) a constant radiation source, (b) a monochromator, (c) a sample holder, (d) a system to check the accuracy of the photometric measurements, (e) an integrating sphere attached to a photomultiplier-digital voltmeter unit, and (f) the data presentation system. Figure 1 illustrates schematically the arrangement of these various components. A circular neutral wedge is placed after the light source to select various levels of radiation intensities required for measurements. A description of the components is presented in the following sections.

a. The Radiation Source. Since the instrument is a single-beam type, it is essential that the radiation source be constant and homogeneous. Additional desirable conditions are: capability of monitoring the current supplied to the source and radiation similar to that from a Planckian radiator. The source is similar in design to that developed and used at NBS by H. J. Kostkowski and R. D. Lee of the Institute for Basic Standards. This source was duplicated in our instrument with the kind assistance of its developers.

The source is used in the spectral range $360 \mathrm{~nm}$ to $800 \mathrm{~nm}$ and consists of a tungsten incandescent filament lamp with a tungsten ribbon $8 \mathrm{~mm}$ long by $2 \mathrm{~mm}$ wide. The connections to the lamp terminals are soldered to minimize contact problems (see fig. 6). The direct current required to operate this lamp at approximately $3000 \mathrm{~K}$ is $18 \mathrm{~A}$ across a $6 \mathrm{~V}$ drop; our source is operated at $5 \mathrm{~V}$ and $15 \mathrm{~A}$. The d.c. power supply is capable of delivering $15 \mathrm{~V}$ and $50 \mathrm{~A}$, and can be operated in constant current or constant voltage modes. To achieve the constant current mode an external sensing resistor of $0.1 \Omega$ and $50 \mathrm{~A}$ and a current control circuit are placed in series with the power supply. A feedback voltage across this resistor is connected to the sensing system. The character

${ }^{3}$ The commercial instruments and parts used in the construction of the spectrophotometer are identified in the addendum. 


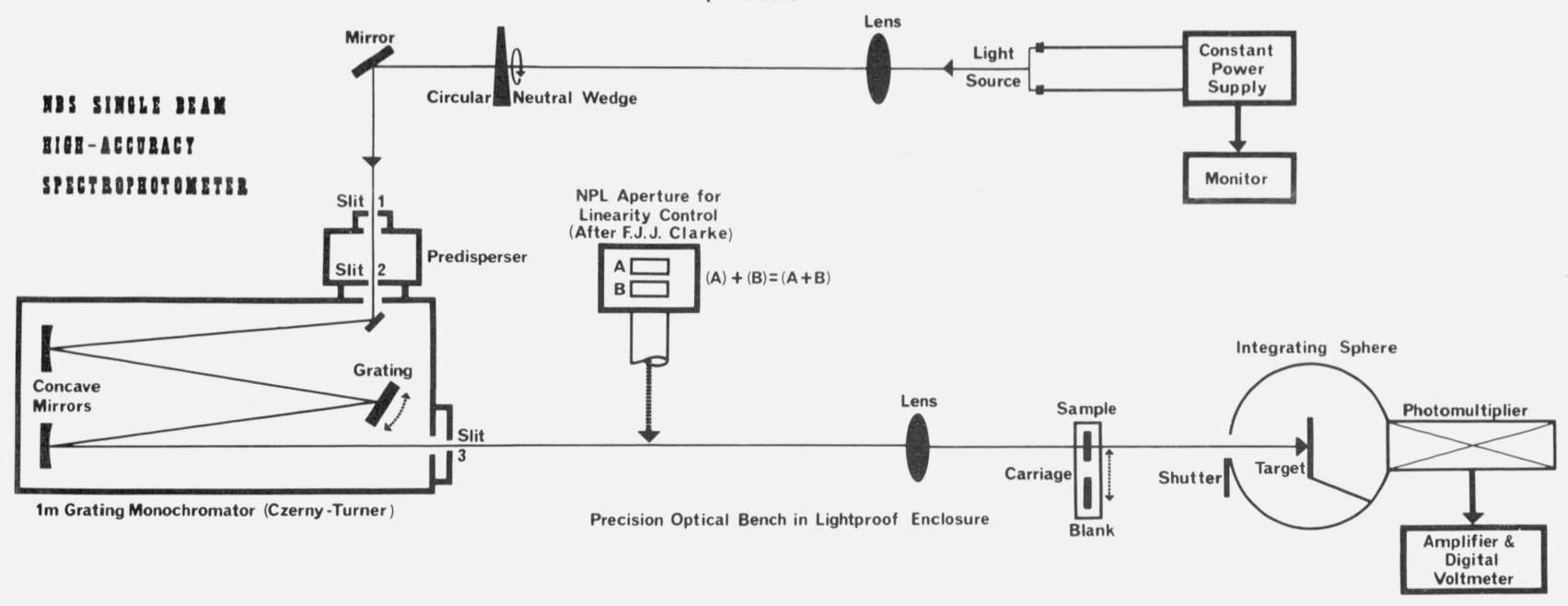

FIGURE 1. Principle of the single beam high accuracy spectrophotometer. The aperture unit is placed on the optical bench only when linearity measurements are performed.

istic of this function is the ability to automatically change its output voltage to maintain a constant current to the load resistor, which, in our case, is the lamp source. The nominal current regulation obtained is better than 0.01 percent, and the stability over an 8 hour period, at constant load temperature, is better than 0.02 percent. The stability of the current delivered to the lamp is monitored with a high accuracy potentiometer used in conjunction with a null meter. This meter is sensitive to variations in the current supplied to the lamp from 1 part in 1000 to 1 part in $1,000,000$ per division (fig. 1 and fig. 14). The potentiometer is connected to the current source across a resistor $(0.01 \Omega$ and $100 \mathrm{~A})$ placed in series with the lamp.

The demagnified (2 to 1 ) image of the ribbon filament is projected on the entrance slit of the predisperser by a fused quartz (nonfluorescent $\mathrm{SiO}_{2}$ ) lens whose focal distance is $254 \mathrm{~mm}$ and diameter is $44 \mathrm{~mm}$. This and the other lenses used in the optical system, were calculated by K. Mielenz of the Institute for Basic Standards at NBS. The lenses are mounted in carriers which permit orientation in any position. A circular neutral wedge is placed between the light source and the predisperser. This wedge, evaporated inconel on a fused quartz disc ( $150 \mathrm{~mm}$ diam), is linear in density and provides a light attenuation of 100 to 1 . The wedge is motor driven ( 1 rev. per s) to select proper radiation intensity levels as required by the measurements (figs. 2, 3, and 4). The radiation source used for measurements in the ultraviolet region to $275 \mathrm{~nm}$ is a single coil tungsten-bromine incandescent lamp (fig. 5) supplied by an adequate power source; below $275 \mathrm{~nm}$, a deuterium discharge lamp is contemplated.

b. The Monochromator. The monochromator is a 1-m Czerny-Turner type grating instrument with a dispersion of $0.8 \mathrm{~nm} / \mathrm{mm}$. The flat grating has 1200 grooves per mm covering a surface of $100 \times 100 \mathrm{~mm}$.
The monochromator is provided with a predispersing attachment to reduce the stray light (fig. 3 ). This pre-

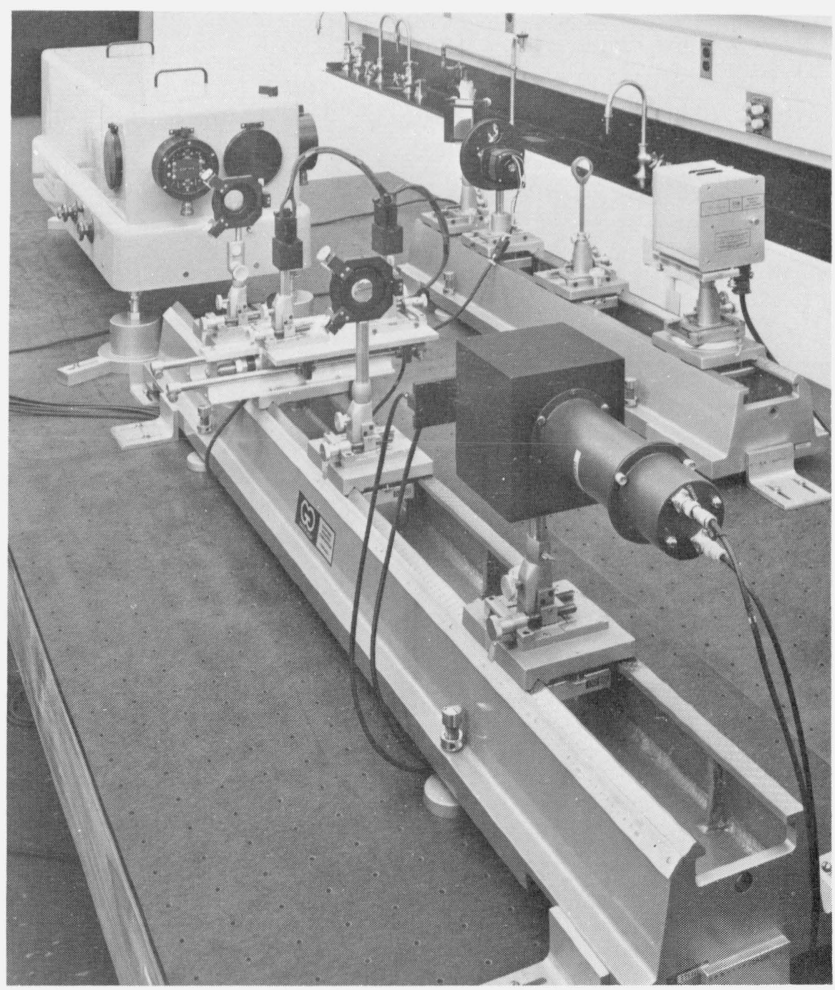

FIGURE 2. General views of the spectrophotometer. Rear: optical bench carrying the tungsten-halogen radiation source used for checking the alignment of optical components, followed by a quartz lens, the circular quartz neutral wedge, and a flat mirror. Left: the 1-m Czerny-Turner grating monochromator (the predisperser is not illustrated here). Front: optical bench carrying a quartz lens, the single-sample and blank carriage, a second quartz lens, and the integrating sphere with the photomultiplier housing. 


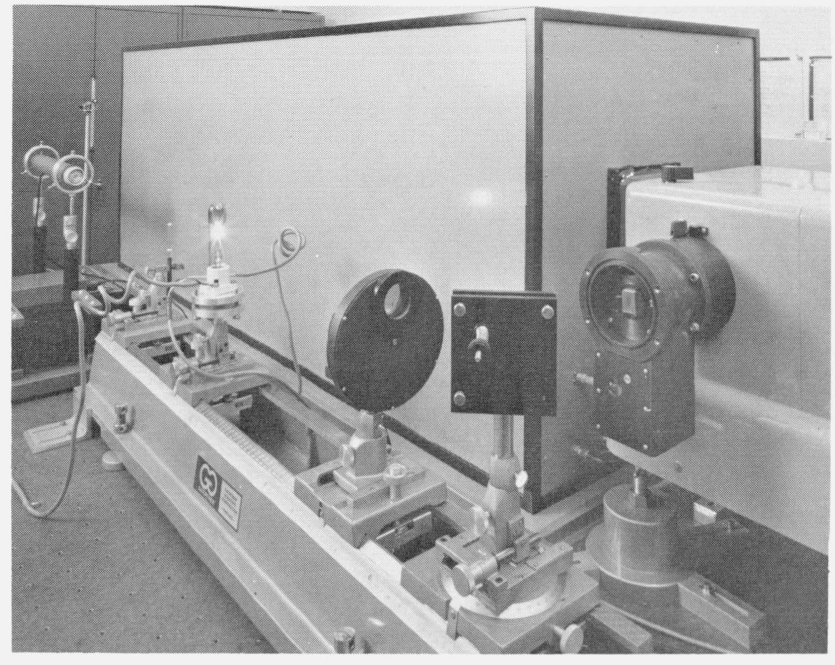

Figure 3. Close view of the tungsten ribbon filament lamp on its adjustable holder, followed by the quartz lens-circular neutral wedge assembly, and by the flat mirror in its adjustable holder. The $30^{\circ}$ quartz prism Littrow-type predisperser is located at the entrance slit of the $1-\mathrm{m}$ grating monochromator. Extreme left: neon gas laser used to check the optical alignment, and mercury discharge lamp for wavelength calibration. When in use, the tungsten ribbon lamp is surrounded by an enclosure with black walls (50 cm x $50 \mathrm{~cm}$ x $70 \mathrm{~cm}$ high). Rear: enclosure containing the optical units illustrated in figure 2 .

disperser is a small quartz prism monochromator connected to the scanning system of the $1-\mathrm{m}$ instrument. A wavelength counter permits readings to $0.1 \mathrm{~nm}$ and the scanning speed can be varied from 0.05 $\mathrm{nm}$ to $200 \mathrm{~nm} / \mathrm{min}$ by a 12 speed synchronous electric motor.

The optical components are placed on precision lathe bed type optical benches which are 160 and $120 \mathrm{~cm}$ long, and are equipped with appropriate carriers provided with $x-y-z$ adjustments.

c. Sample Carrying Systems. The spectrophotometer is provided with two sample carrying systems. Une system measures one sample and its blank, while the other system permits sequential measurements for seven samples and eight reference reading positions against air, and can be operated manually or automatically through a computer interfaced with the instrument.

The single sample carrying unit consists of a platform provided with two vertical holders which can accept $\frac{3}{4}$-in $(14 \mathrm{~mm})$ rods and a variety of sample supports (fig. 2). These holders can be moved laterally through a rack and pinion arrangement. The platform is mounted on 4 ball bushings which ride on two horizontal rods and can be moved pneumatically across the optical axis. The pneumatic operation was recommended by G. E. Moore and J. T. Sterling of the Institute for Materials Research at NBS and by L. Owen, a guest worker at NBS. The travel distance is 8 in $(20 \mathrm{~cm})$ and the linear movement is smooth; the position of the platform and the sample in and out of the optical beam, can be reproduced within $0.025 \mathrm{~mm}$. This unit is illustrated in figure 2

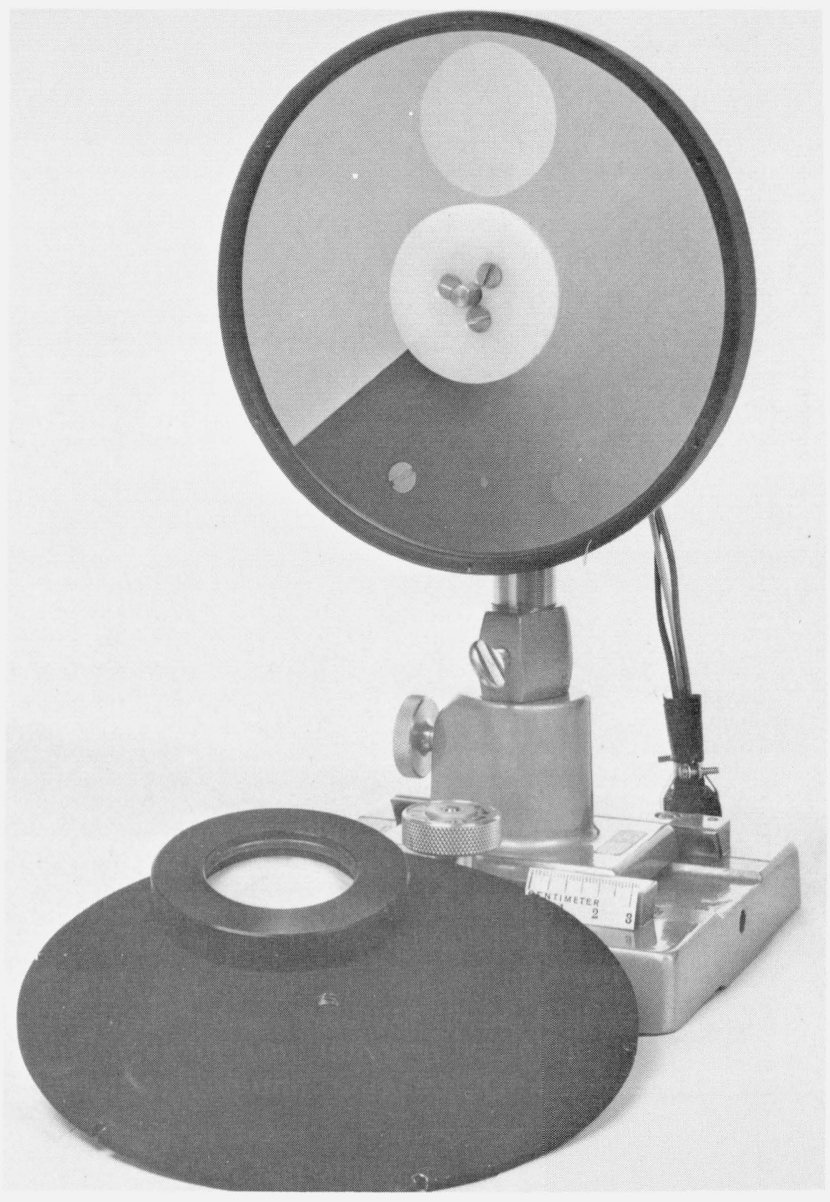

Figure 4. Close view of the circular, neutral wedge. The front plate which carries the fused silica lens was removed to show the fused silica disc with the evaporated metal layer.

and is located between the two quartz lenses. The sample holder is designed to accept conventional solid or liquid filter holders which fit most spectrophotometers. These holders are provided with a thermostating jacket, and can be rotated in the horizontal plane through a $10 \mathrm{~cm}$ diameter rotating table.

A filter holder which permits the rotation and scanning of the sample in the $x-y$ direction is also available (fig. 7). It is provided with micrometer screws having a total linear motion of $25 \mathrm{~mm}$ with $0.01 \mathrm{~mm}$ per division. The seven-sample carrying unit is illustrated in figures 8 and 9 and consists of a semicircular aluminum-alloy plate placed horizontally on an appropriate carrier on the optical bench along the optical axis. This plate, which is $32 \mathrm{~cm}$ in diameter and $2.5 \mathrm{~cm}$ thick, can be rotated clockwise through a pneumatically operated precision ratchet system in increments of $12^{\circ}$. The stepwise rotation utilizes a solenoid valve which is operated electrically by a switch located outside the enclosure. This switch can be operated manually or automatically by computer (fig. 14). 


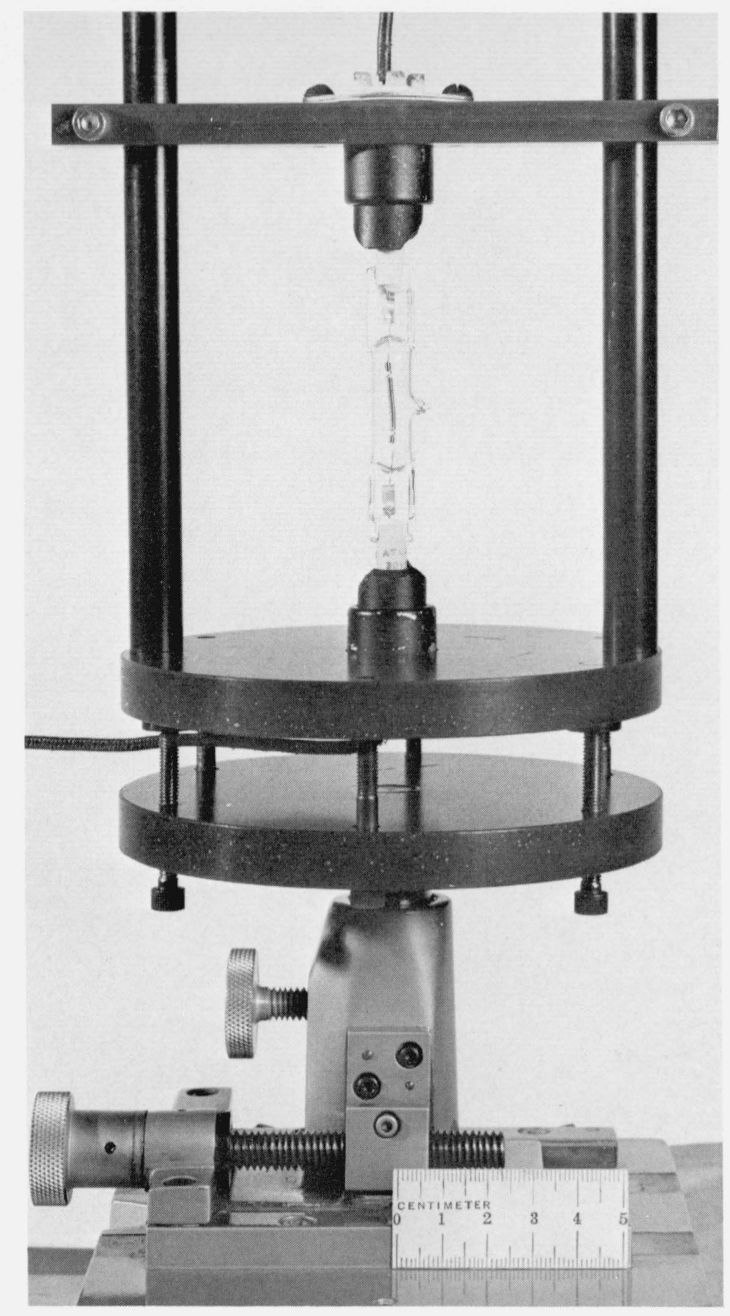

Figure 5. Single coil tungsten halogen lamp in the adjustable holder.

The semicircular plate carries seven sample holders similar to those used for the single sample system described earlier. The holders are placed at $24^{\circ}$ intervals and are separated by blank spacings. About 1 atm of air pressure is used to operate the plate and the rotation is set at $2 \mathrm{~s}$ per $12^{\circ}$ step when the automatic computer operating mode is used.

d. System to Check the Accuracy of the Photometric Reading. Since the high accuracy spectrophotometer is single beam, accurate photometric data are obtained when there is a linear relation between the measured radiation flux and the corresponding response of the photodetector.

Linearity of photodetectors can be measured by several means: the inverse square law $[7,15]$; the use of optical elements having a known transmittance which can be determined by other means [17] and the light addition principle of Elster and Geitel using a plurality of light sources $[5,6,8,9,10,13,18,19,20,28,31,33$, $34]$ or multiple apertures $[11,12,14,16,21,23,25,26$, $27,30]$. A novel approach to the problem of accurate

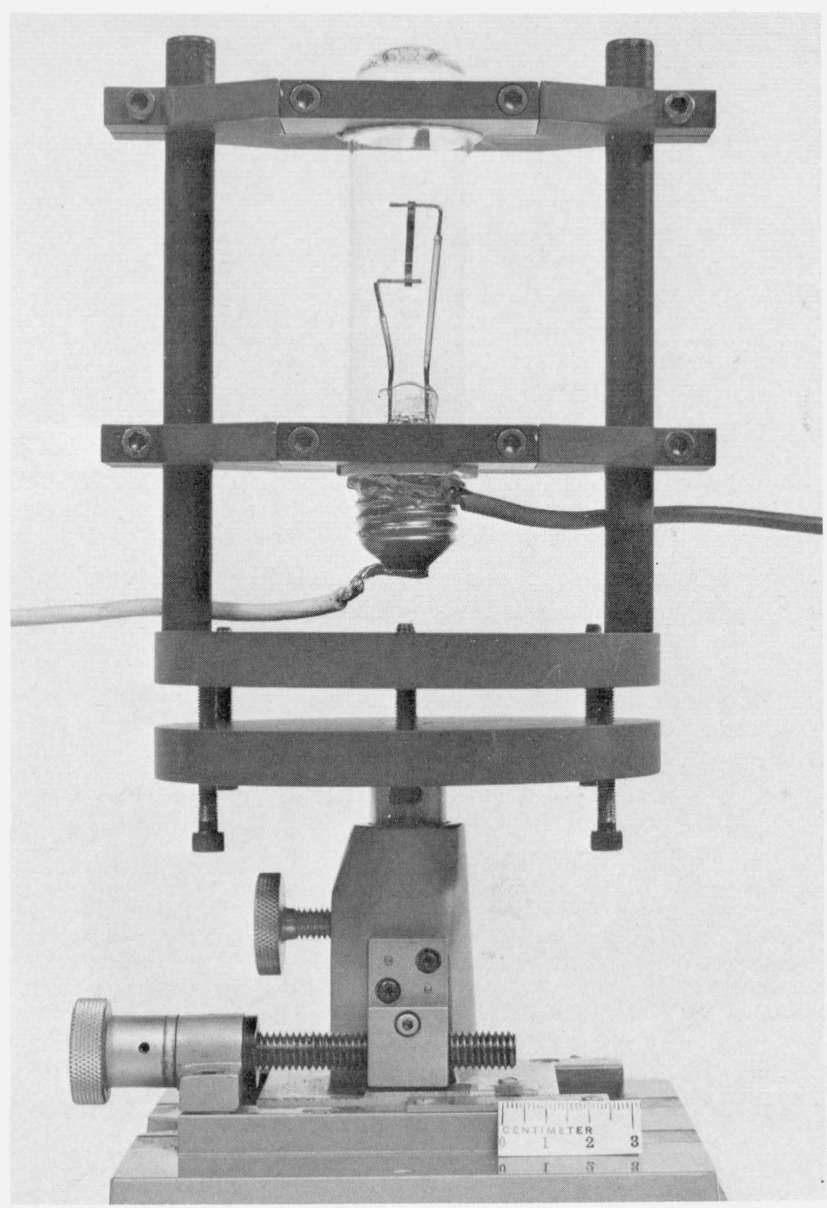

FIGURE 6. The tungsten ribbon filament lamp in the newly designed adjustable holder. The platform which carries the lamp is similar to that described in figure 5 and can be oriented in the horizontal plane through the six screws spaced around the edges of the platform at $60^{\circ}$ intervals. Three screws push the platform while the other three pull.

The current-supplying wires are soldered directly to the lamp terminals to eliminate contact problems.

photometric measurements was described by O. C. Jones and F. J. J. Clarke [24, 29] and by F. Desvignes and J. Ohnet [32]. A critical discussion of some aspects of accurate spectrophotometry will be found in an NBS manuscript by. Gibson and associates [22]. The radiation addition principle, using two apertures with one source of radiation, was chosen for our work. The aperture method for checking the linearity of photometric data was in use at the National Physical Laboratory from about 1930 onwards, and one form of it was described by Preston and Cuckow [11] in conjunction with a single beam spectrophotometer, using a five aperture screen. One year later, Buchmüller and König [12] described and used a two aperture unit. At NBS, Barbrow [14] used a 10 aperture arrangement, while Harding [16] and Cordle and Habell [25] at NPL described a two aperture system. Multiapertures were used by Hoppmann [21], Bischoff [23], Sanders [26] and Nonaka and Kashima [27]. Finally, Clarke [30] 


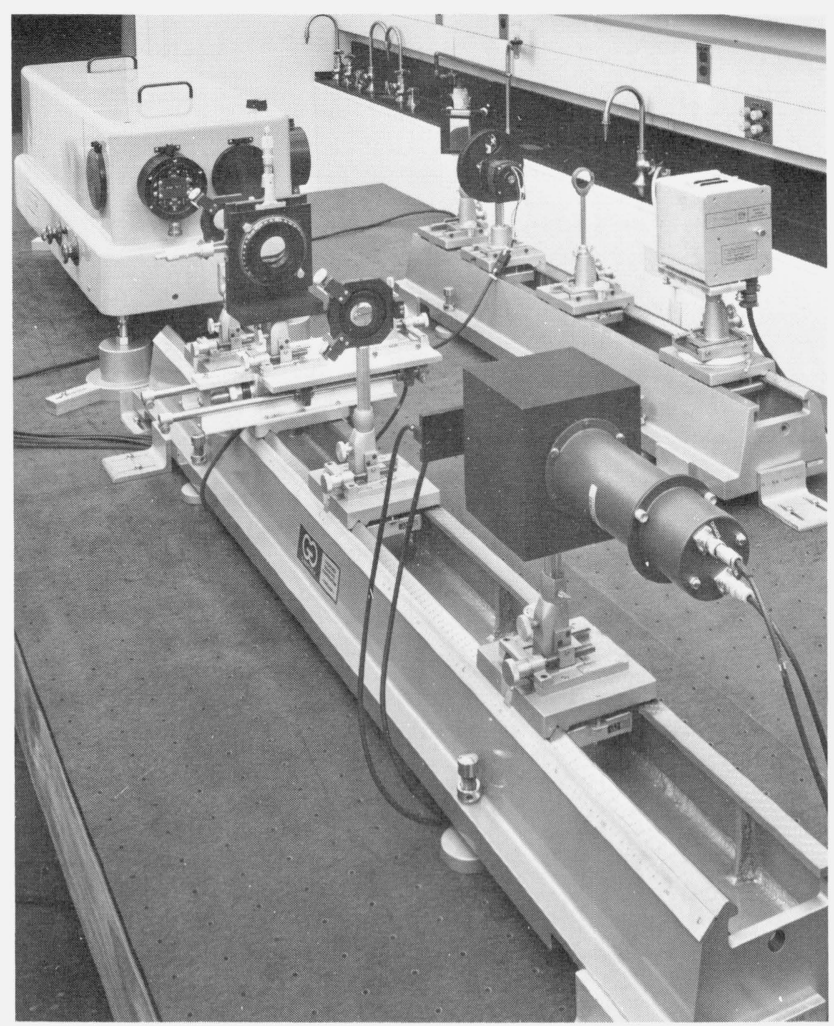

Figure 7. Same as figure 2 except tor the sample holder which in this case is capable of rotating the sample $360^{\circ}$ and to displace it in the $x-y$ direction through the micrometer screws.

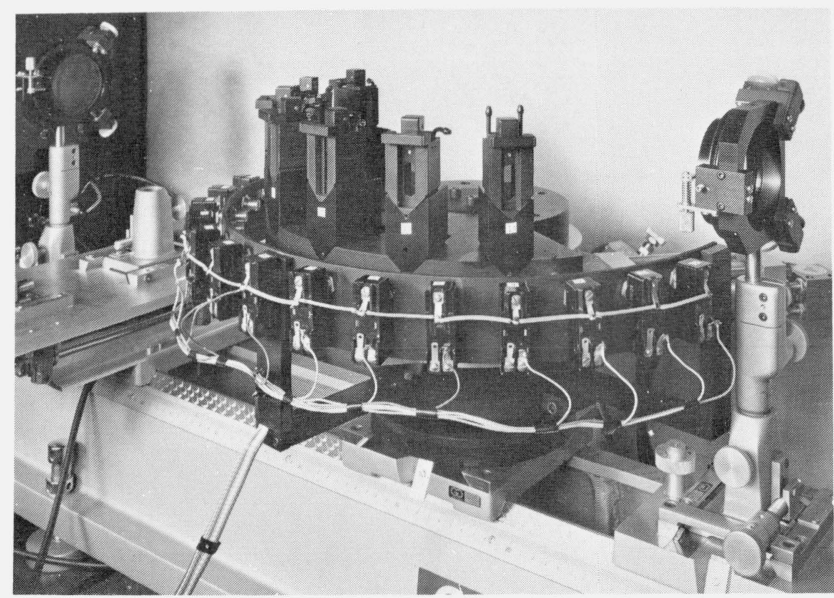

FIGURE 8. Circular platform carrying seven filter holders. The 15 position switches ( 7 sample positions and 8 blank positions) are visible along with the two quartz lenses. The exit slit of the monochromator is at left.

discussed in detail the use of a two aperture system to check the accuracy of photometric data obtained on the spectrophotometer at NPL. It is this two aperture system which is used at NBS.

The two aperture unit consists of a metal plate (130 $\mathrm{mm}$ by $100 \mathrm{~mm}$ ) containing two rectangular

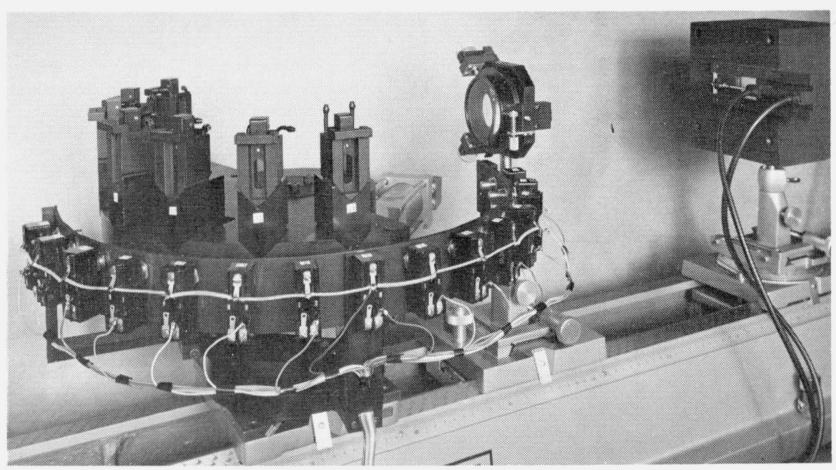

FIGURE 9. Same as figure 8. The pneumatic cylinder which rotates the circular platform through a ratchet mechanism is visible at the rear of the platform. The integrating sphere with its pneumatic shutter is seen at right.

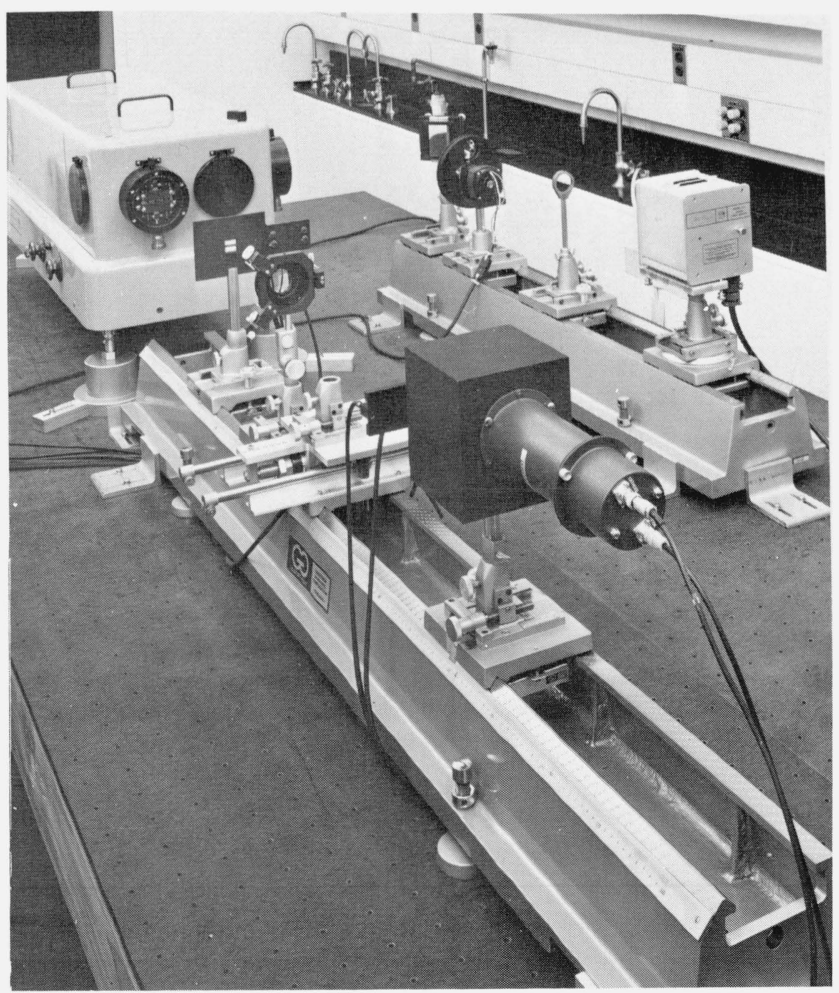

Figure 10. Same as figure 2. In this case the dual-aperture unit for linearity control is located on the optical bench after the exit slit of the monochromator.

windows, $\mathrm{A}$ and $\mathrm{B},(20 \mathrm{~mm}$ by $8 \mathrm{~mm})$ located one above the other (figs. 10, 11, 12). Each aperture can be closed by a light-tight shutter which is operated pneumatically by remote control (fig. 14). The aperture plate is placed in the optical path after the exit slit of the monochromator and within the optical solid angle of the instrument. The image of the apertures is then projected on the target of the integrating sphere. A fused quartz lens with a focal distance of $190 \mathrm{~mm}$ and a diameter of $60 \mathrm{~mm}$ is used for this purpose. The arrangement is illustrated in figure 10. No optical element 


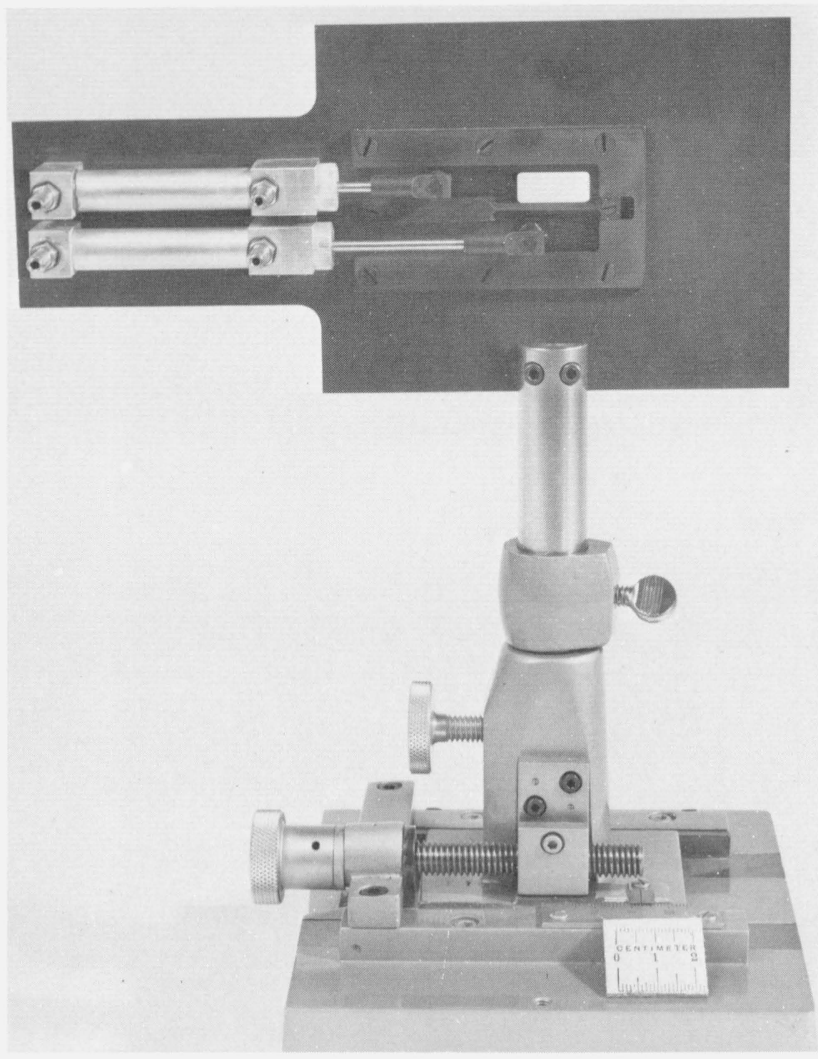

FIGURE 11. Detail of the dual-aperture unit showing its construction and the pneumatic system which operates the two shutters. One aperture is open, the other is ciosed.

should be placed between the aperture plate and the monochromator. The linearity check consists of measuring the photocurrent produced when aperture $\mathrm{A}$ is open then closed, and then aperture $\mathrm{B}$ is open and then closed. The value of $(A)+(B)$ is compared with the values obtained with both apertures $(A+B)$ open. If the system is linear these two values should be identical:

$$
(A)+(B)=(A+B) .
$$

If this is not the case, the system shows nonlinearity which is proportional to the amount by which the sum of $(A)+(B)$ differs from $(A+B)$. This difference is then used to correct the transmittance values measured on the solid or liquid filters.

e. Integrating Sphere and Photomultiplier Arrangement. The radiations emitted from the exit slit of the monochromator and passing through the aperture or the filter are received on the target of the integrating sphere. This sphere is illustrated in figures $2,7,9$, and 10. A block of aluminum made from identical halves was cut to produce a half sphere in each block. The halves were joined together to form a hollow sphere. Its diameter is $125 \mathrm{~mm}$ and a target, made from a circular plate, $35 \mathrm{~mm}$ in diameter, is located at the center of the sphere. The front surface of the sphere has a $20 \mathrm{~mm}$ diameter opening. This

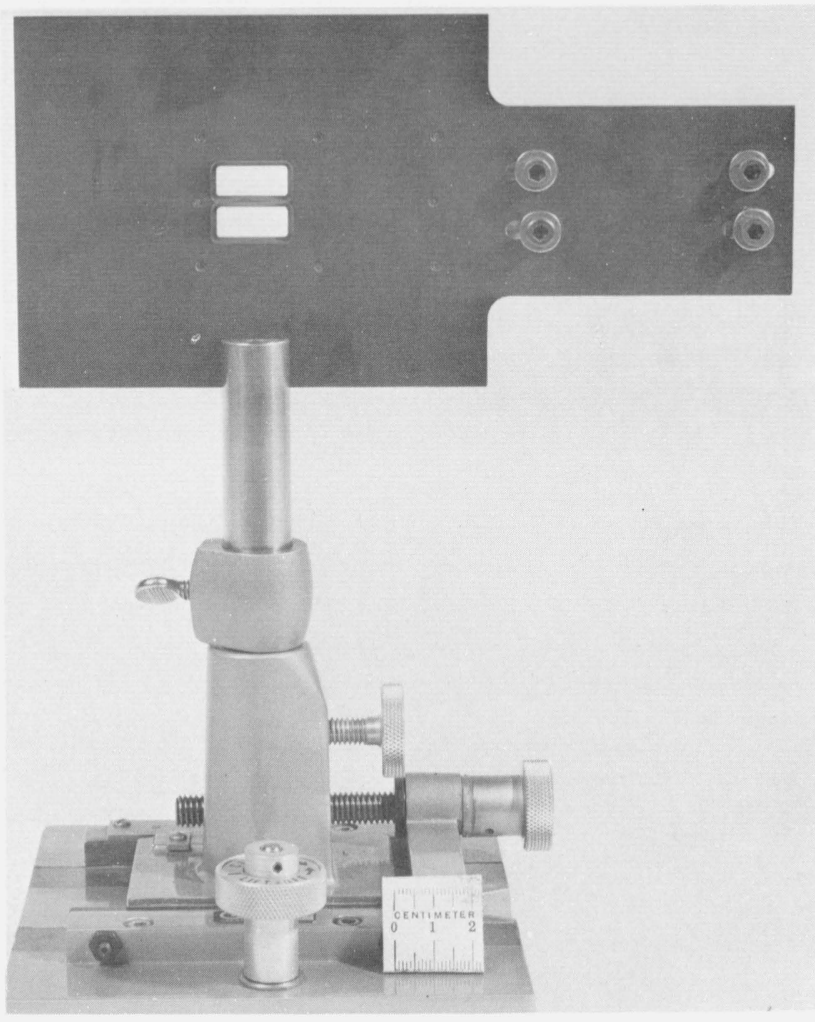

Figure 12. Front view of the dual-aperture unit, with both apertures open.

opening can be closed by a shutter which is operated remotely by a pneumatic system. A $50 \mathrm{~mm}$ diameter opening is at the opposite end to which the housing of the photomultiplier is attached by an " $O$ " ring to provide a light-tight joint. The inside of the sphere is coated using a suspension of $\mathrm{BaSO}_{4}$; the outside is painted black.

Under these circumstances the sensitive surface of the photodetector receives the radiations originating from the exit slit of the monochromator only after these radiations have undergone at least two diffuse reflections.

The photomultiplier is a $50 \mathrm{~mm}$ flat-faced, silica end window tube with a $44 \mathrm{~mm}$ cathode and 11 venetian blind dynodes having CsSb secondary emitting surfaces. The cathode is an $\mathrm{S}-20$ or tri-alkali type. The spectral range of this tube is from below $200.0 \mathrm{~nm}$ to $850.0 \mathrm{~nm}$. The operating voltage used is $850 \mathrm{~V}$. The photomultiplier output is supplied to a current-tovoltage converter consisting of an operational amplifier with high precision feedback resistors with values of $10^{6}, 3 \times 10^{6}, 10^{7}, 3 \times 10^{7}$, and $10^{8} \Omega$. Dark current compensation is also available. This electronic system, described in figure 13 was designed and assembled by K. W. Yee of the NBS Electronic Instrumentation Section. The output from the currentto-voltage unit is connected to a digital voltmeter, illustrated in figure 14, with one microvolt resolution on the $1 \mathrm{~V}$ full scale range. 


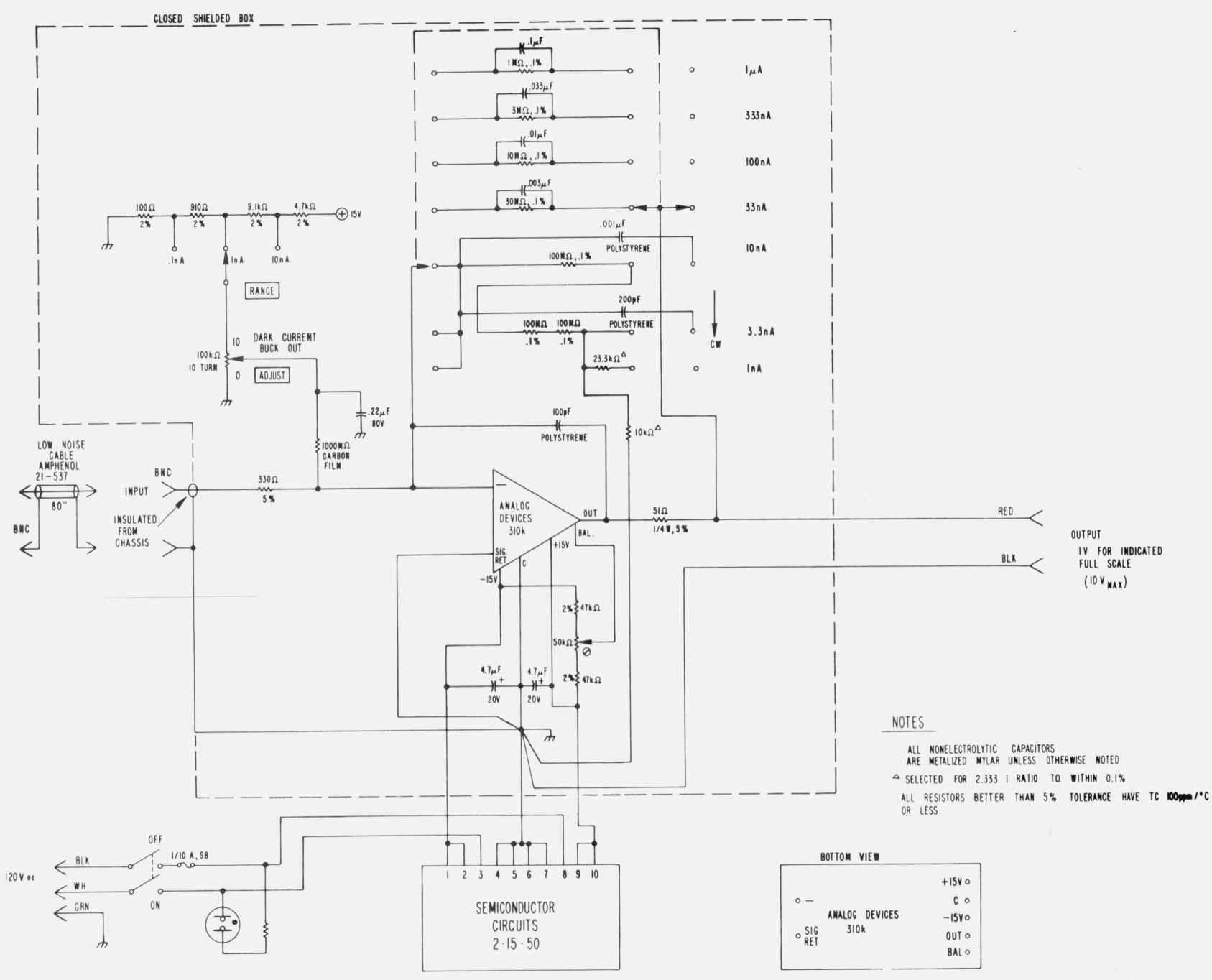

Figure 13. Schematic of the current-to-voltage circuitry. Courtesy of K. W. Yee.

The optical components located after the exit slit of the monochromator, including the photomultiplier tube, are enclosed in a light-tight box $200 \mathrm{~cm}$ long, 70 $\mathrm{cm}$ wide and $76 \mathrm{~cm}$ deep (fig. 3). The removable front panel is provided with a sliding door to permit rapid access to the filter-holder system. The box contains outlets for the compressed air which operates the apertures, sample carriage and integrating sphere shutter, and for the electrical connection from the photomultiplier. The inside walls are lined with thermal insulation painted black. When in use, all nonblack metal parts are covered with a black cloth to reduce stray light. The entire equipment is placed on a vibration isolation table $3.66 \mathrm{~m}$ by $1.52 \mathrm{~m}$. The optical benches and the monochromator are secured by stops which are attached to the table surface. The alignment of the optical parts is made and checked periodically with a low-power laser shown in figure $3(\mathrm{CW}$ gas laser, output power $2 \mathrm{~mW}, \lambda 6328 \AA$ ) and with a high intensity tungsten-halogen lamp shown in figure 5 . f. Data Collection and Presentation Systems. The data output from the digital voltmeter (DVM), corresponding to the current generated at the photomultiplier tube by the radiations passing through the aperture system $(A, B, A+B)$ or the samples $(I)$ and blanks $\left(I_{0}\right)$, can be obtained by visual means or computer operation. Both methods have been used in this work with good results. In the visual mode, the operator examines the digital voltmeter display and takes a mental average of the data. The display rate is adjusted to about one reading per second.

When measurements are taken by computer, the display of the digital voltmeter is adjusted to a faster rate; for instance, 10 to 20 data per second, depending on the capabilities of the instrument and measurement requirements. In our work, we use 10 data per second and collect 50 individual data for each measurement. This information is fed to the computer which calculates and prints the results as averages with the corresponding standard deviation, relative standard 


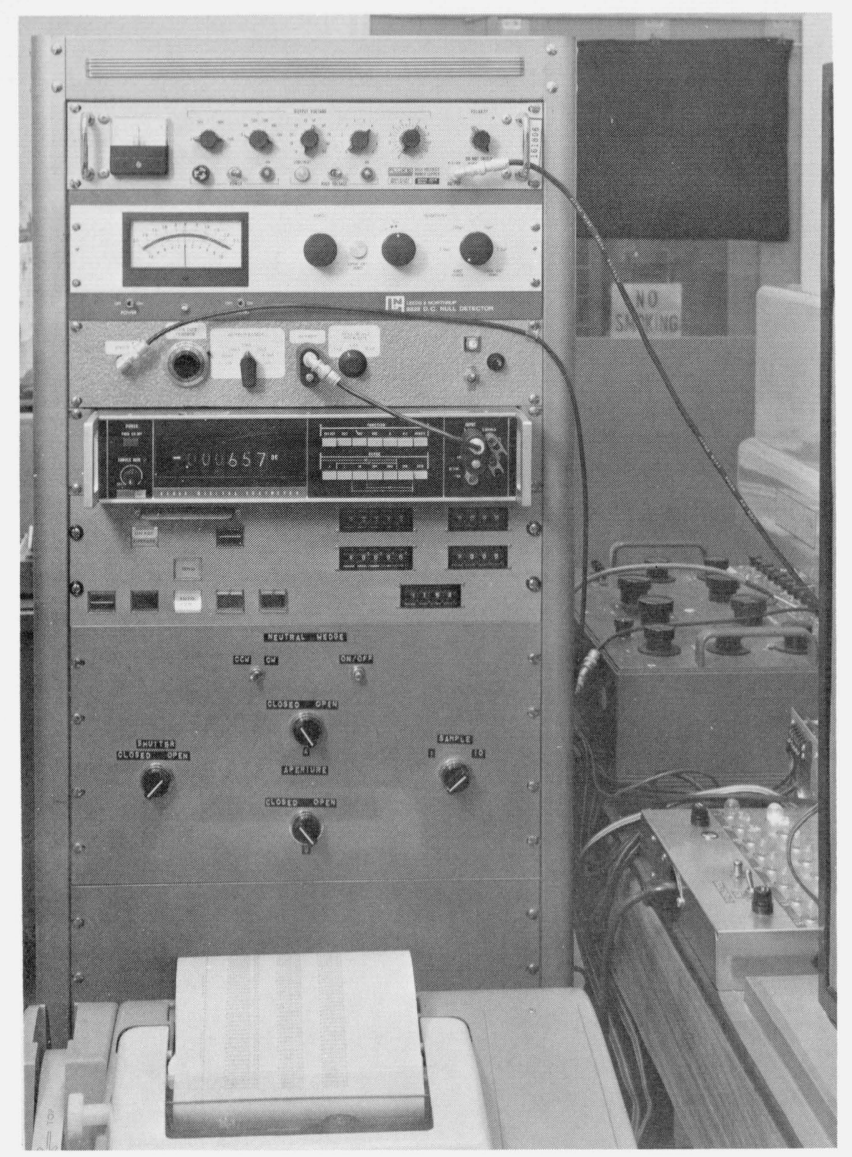

Figure 14. Console containing the power supply for the photomultiplier tube, the dc null detector, the current-to-voltage converter, the digital voltmeter, the command panel for computer operation, and the command panel for the pneumatic operation of the shutter, aperture system, and single sample carriage. The electric switches for operating the circular neutral wedge are also located on this panel.

Middle right: potentiometer for monitoring the dc current supplied to the tungsten ribbon filament lamp.

At bottom left: teletype for data presentation.

Right: light panel which indicates the position of the automatic seven sample holder.

deviation, and sample position number to identify the measurement. When transmittance measurements are made on individual samples or when linearity checks are performed, the readings are initiated manually for every position. When the seven sample holder is used for sequential measurements, the operation is performed automatically by the computer. It is programmed to take a predetermined number of individual DVM readings (50), print the arithmetic average, followed by the standard deviation, relative standard deviation, percent transmittance and sample position (fig. 15). At the conclusion of each measurement, the computer initiates a signal which rotates the holder to the next position. This is followed by the data taking and sample changing sequence until the measurements are stopped manually or automatically by a provision made in the computer program.
CALIBRATION OF SRM930 AT 440 NM

SAMPLE NUMBER AND POSITION:

1-70 IN 2; 1-79 IN 4; 2-79 IN 6; REFERENCE IN 8; 3-79 IN 10;

$1-91$ IN $12 ; 3-91$ IN 14
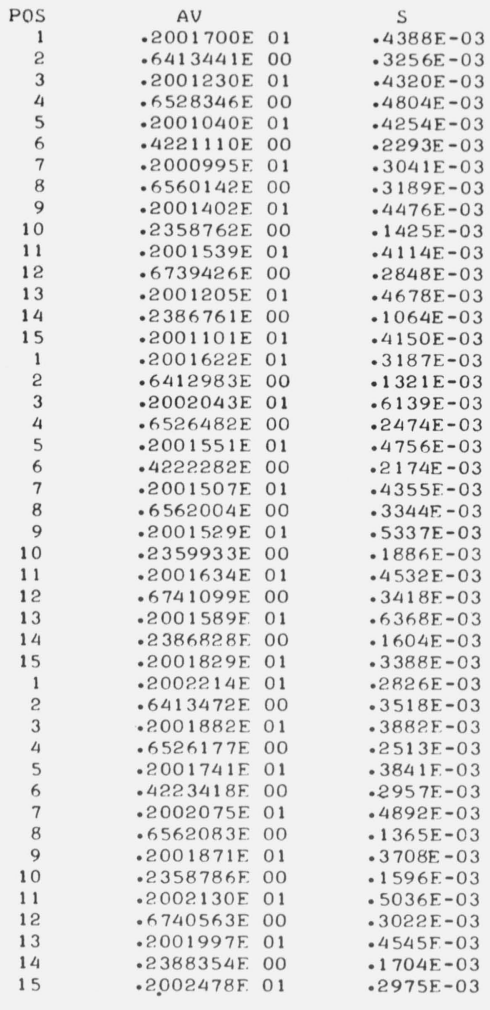

S/AV

$.2192 \mathrm{E}-03$

$.5077 \mathrm{E}-03$

$.2159 \mathrm{E}-03$

$.7359 \mathrm{E}-03$

$.2126 \mathrm{E}-03$

$.5432 \mathrm{E}-03$

$.1520 \mathrm{E}-03$

$.4861 \mathrm{E}-03$

. $2236 \mathrm{E}-03$

$.6039-03$

-

- 2055 E-OS

- $4226 \mathrm{E}-03$

- $2338 \mathrm{E}-03$

$.4456 \mathrm{E}-03$

- $2074 \mathrm{E}-03$

- 1592E-03

-2060E-03

. $3067 \mathrm{E}-03$

- 3790E-03

-2376E-03

$-5149 \mathrm{E}-03$

- $176 \mathrm{E}-03$

- $176 \mathrm{~F}-03$

- S095E-03

- $2667 \mathrm{~F}-03$

- 7992E-03

- 22.64E-03

-5070F-03

. $3182 \mathrm{~F}-03$

. $6720 \mathrm{E}-03$

$.1693 \mathrm{~F}-03$

. $1412 \mathrm{E}-03$

- 1412E-03

-

- 1939E-03

- $3851 \mathrm{E}-03$

- 1919E-03

- 7000E-03

. $2443 \mathrm{E}-03$

- $2081 \mathrm{E}-03$

$.1852 \mathrm{~F}-03$

$.6767 \mathrm{E}-03$

$.2515 E-03$

$.4484 \mathrm{E}-03$

. $4484 \mathrm{~F}-03$

- $2270 \mathrm{E}-03$

$.7133 \mathrm{E}-03$
$.1485 \mathrm{~F}-03$

PERCENT T

32.044

32.623

21.095

32.781

11.785

33.674

11.927

32.036

32.603

2.1 .095

32.785

11.790

33.678

11.924

32.035

32.601

21.097

32.778

11.782

33.668

11.928

Figure 15. Computer data presentation.

The programming of the entire computer operation was developed by J. Aronson, R. Freemire, and J. Wing. The computer-instrument interfacing was performed by F. Ruegg and R. Shideler of the NBS Analytical Chemistry Division, Technical Service Group, under the supervision of J. DeVoe.

\section{Stability of the Electronic System}

As a rule, before taking measurements with the spectrophotometer, a warmup period of one hour is required. The room temperature is kept at $24 \pm 1{ }^{\circ} \mathrm{C}$, and the relative humidity is 35 percent. The particulate matter is controlled through special filters which rates the room in the 100,000 class.

The dark current of the photomultiplier tube was measured by taking 15 replications each consisting of the average of 50 individual digital voltmeter readings. These measurements were made using $850 \mathrm{~V}$ at the anode. The average dark current under these circumstances produced $0.000682 \mathrm{~V}$ with a relative standard deviation of 0.71 percent.

In all of our work, a dark current buck-out arrangement was used. A series of measurements were performed to determine the stability of this dark current compensation. To this effect, 15 consecutive measurements, each representing the average of 50 indi- 
vidual digital voltmeter readings, were made and the average dark current value was $0.000024 \mathrm{~V}$ with a relative standard deviation of 23.1 percent.

Four tests were made to determine the stability of the electronic system and the radiation source using the computer data acquisition mode.

a. Stability of the Current-to-Voltage Converter. A constant voltage was supplied to the converter using the dark current compensation provided on the unit. Fifty individual measurements were taken every 5 seconds and the average value was printed along with its percent standard deviation. The measurements were then repeated 15 times and an average of the 15 values was calculated along with the corresponding percent standard deviation. These measurements were then repeated three times. The results are summarized in table 1 . This table also presents the values for the first group and the average values and corresponding percent standard deviation for the two consecutive groups. It can be seen from the stability of the current-to-voltage unit that measurements can be performed with a reproducibility of about 0.0012 (at the $67 \%$ confidence level) expressed as percent standard deviation for a single determination. The time interval between the first and last group of measurements was $15 \mathrm{~min}$.

TABLE 1. Stability of the current-to-voltage converter alone measured in three groups of 15 replications each

\begin{tabular}{|c|c|c|}
\hline Replication & $\begin{array}{l}\text { Average of } 50 \text { individual } \\
\text { measurements; volts }\end{array}$ & $\begin{array}{c}\text { Percent standard } \\
\text { deviation }\end{array}$ \\
\hline 1 & 1.003494 & $0.0013_{6}$ \\
\hline 2 & 1.003496 & $0.0012_{9}$ \\
\hline 3 & 1.003482 & $0.0014_{6}$ \\
\hline 4 & 1.003507 & $0.0011_{1}$ \\
\hline 5 & 1.003515 & $0.0013_{4}$ \\
\hline 6 & 1.003508 & $0.0013_{6}$ \\
\hline 7 & 1.003497 & $0.0011_{8}$ \\
\hline 8 & 1.003498 & $0.0013_{3}$ \\
\hline 9 & 1.003505 & $0.0011_{0}$ \\
\hline 10 & 1.003510 & $0.0014_{2}$ \\
\hline 11 & 1.003518 & $0.0013_{3}$ \\
\hline 12 & 1.003521 & $0.0012_{0}$ \\
\hline 13 & 1.003522 & $0.0013_{1}$ \\
\hline 14 & 1.003507 & $0.0012_{6}$ \\
\hline 15 & 1.003527 & $0.0013_{7}$ \\
\hline Average of replications & 1.003507 & \\
\hline $\begin{array}{l}\text { Percent standard } \\
\text { deviation }\end{array}$ & 0.0012 & First group \\
\hline Average of replications & 1.003535 & \\
\hline $\begin{array}{l}\text { Percent standard } \\
\text { deviation }\end{array}$ & 0.0015 & Second group \\
\hline Average of replications & 1.003545 & \\
\hline $\begin{array}{l}\text { Percent standard } \\
\text { deviation }\end{array}$ & 0.0010 & Third group \\
\hline
\end{tabular}

b. Stability of the Current-to-Voltage Converter Plus the Photomultiplier Tube Supplied with $850 \mathrm{~V}$ and in Total Darkness. The measurements were made as previously described and the results are presented in table 2.

c. Stability of the Current-to-Voltage Converter and the Photomultiplier Tube Supplied with $850 \mathrm{~V}$ and Exposed to the Radiation of a Tritium Activated Fluorescence Source. A constant radiation source consisting of a tritium activated phosphor was placed before the integrating sphere and a series of measurements were taken following the technique described above. Table 3 shows the results. d. Stability of the Current-to-Voltage Converter, the Photomultiplier Tube Supplied with $850 \mathrm{~V}$, and the Tungsten Ribbon Filament Lamp. The same measuring procedure as mentioned in $\mathrm{a}, \mathrm{b}$, and $\mathrm{c}$ was used here. In this case, however, the incandescent tungsten lamp was used as the source of radiation. Table 4 summarizes the results of four groups of measurements over a period of 20 min. This last series of measurements indicate that the single-beam spectrophotometer is capable of producing measurements of radiation fluxes with a percent standard deviation of about $0.022_{5}$ for single measurements with $2.00 \mathrm{~V}$ at the photomultiplier tube anode. 
TABLE 2. Stability of the current-to-voltage converter and the photomultiplier tube at $850 \mathrm{~V}$ in total darkness

\begin{tabular}{|c|c|c|}
\hline Replication & $\begin{array}{c}\text { Average of } 50 \text { individual } \\
\text { measurements; volts }\end{array}$ & $\begin{array}{c}\text { Percent standard } \\
\text { deviation }\end{array}$ \\
\hline 1 & 1.012329 & $0.027_{1}$ \\
\hline 2 & 1.012342 & $0.048_{8}$ \\
\hline 3 & 1.012322 & $0.027_{2}$ \\
\hline 4 & 1.012320 & $0.033_{8}$ \\
\hline 5 & 1.012394 & $0.043_{5}$ \\
\hline 6 & 1.012421 & $0.015_{3}$ \\
\hline 7 & 1.012404 & $0.018_{4}$ \\
\hline 8 & 1.012406 & $0.029_{6}$ \\
\hline 9 & 1.012365 & $0.019_{6}$ \\
\hline 10 & 1.012402 & $0.019_{1}$ \\
\hline 11 & 1.012465 & $0.025_{2}$ \\
\hline 12 & 1.012412 & $0.06 \mathrm{l}_{5}$ \\
\hline 13 & 1.012451 & $0.023_{5}$ \\
\hline 14 & 1.012417 & $0.029_{8}$ \\
\hline 15 & 1.012481 & $0.024_{8}$ \\
\hline \multirow{3}{*}{$\begin{array}{l}\text { Average of replications } \\
\text { Percent standard } \\
\text { deviation }\end{array}$} & 1.012395 & \multirow{3}{*}{ First group } \\
\hline & & \\
\hline & 0.0050 & \\
\hline \multirow{3}{*}{$\begin{array}{l}\text { Average of replications } \\
\text { Percent standard } \\
\text { deviation }\end{array}$} & 1.012467 & \multirow{3}{*}{ Second group } \\
\hline & & \\
\hline & 0.0033 & \\
\hline \multirow{2}{*}{$\begin{array}{l}\text { Average of replications } \\
\text { Percent standard } \\
\text { deviation }\end{array}$} & 1.012510 & \multirow[b]{2}{*}{ Third group } \\
\hline & 0.0035 & \\
\hline
\end{tabular}

In these measurements the stability of the direct current (nominal $5 \mathrm{~V} ; 14 \mathrm{~A}$ ) supplied to the tungsten ribbon lamp was monitored with the potentiometer, and the variation of this current was less than one part in $10^{5}$ during a series of 15 consecutive measurements $(5 \mathrm{~min})$.

Following the four stability tests discussed earlier, a consecutive series of six measurements were made to determine the reproducibility of transmittance measurements. To this effect seven Schott NG-4 neutral glass filters were placed in the automatic sample carrying system and the data acquisition and sample changing operations were performed automatically through the computer unit. As mentioned previously, the sample carrying system can accept seven samples in positions $2 ; 4 ; 6 ; 8 ; 10 ; 12 ; 14$, and eight intermediate positions $1 ; 3 ; 5 ; 7 ; 9 ; 11 ; 13 ; 15$. The odd numbers correspond to measurements of the nonattenuated radiation beam passing through air and are marked $I_{0}$, while the even numbers correspond to measurements of the attenuated radiations after passing through the absorbing material and are marked $I$. The uncorrected transmittance, $T$, is then

$$
T=\frac{I}{I_{0}}
$$

The radiation flux from the tungsten ribbon filament lamp was attenuated with the circular neutral wedge until a photocurrent corresponding to about $2.0020 \mathrm{~V}$ was obtained for the nonattenuated beam $I_{0}$. The photomultiplier tube was supplied with $850 \mathrm{~V}$ and the 30 $\mathrm{M} \Omega$ resistor was used at the current-to-voltage converter. For every position, 50 digital voltmeter readings were taken by the computer at a rate of 10 to 15 per second. The average value was printed along with the sample position, the standard deviation, the relative standard deviation, and the transmittance values for the glass filters $2 ; 4 ; 6 ; 8 ; 10 ; 12$; and 14 :

$$
T_{2}=\frac{I_{2}}{\frac{I_{1}^{0}+I_{3}^{0}}{2}} ; T_{4}=\frac{I_{4}}{\frac{I_{3}^{0}+I_{5}^{0}}{2}} ; T_{6}=\frac{I_{6}}{\frac{I_{5}^{0}+I_{7}^{0}}{2}} ; \text { etc. } \ldots
$$

until the seven glass filters were measured. This sequence was repeated six times and the results are given in table 5 .

As can be seen from these data, the reproducibility of sequential transmittance measurements can be performed with an average standard deviation of 0.010 percent for a single determination.

\section{Wavelength Calibration}

The wavelength scale of the monochromator is provided with a counter which indicates wavelength directly in ångstroms. This counter is checked for 
TABLE 3. Stability of the current-to-voltage converter and the photomultiplier tube at $850 \mathrm{~V}$ and exposed to the radiation of a tritium activated fluorescent source

$\left.\begin{array}{ccc}\text { Replication } & \begin{array}{c}\text { Average of 50 individual } \\ \text { measurements; volts }\end{array} & \begin{array}{c}\text { Percent standard } \\ \text { deviation }\end{array} \\ 1 & 1.536345 & 0.027_{5} \\ 2 & 1.536326 & 0.030_{2} \\ 3 & 1.536196 & 0.022_{8} \\ 4 & 1.536289 & 0.023_{5} \\ 5 & 1.536106 & 0.030_{9} \\ 6 & 1.536117 & 0.031_{4} \\ 7 & 1.535916 & 0.025_{1} \\ 8 & 1.536065 & 0.023_{8} \\ 9 & 1.536179 & 0.029_{3} \\ 10 & 1.536003 & 0.023_{3} \\ 11 & 1.536083 & 0.021_{5} \\ 12 & 1.535961 & 0.026_{3} \\ 13 & 1.536052 & 0.031_{3} \\ 15 & 1.536095 & 0.026_{6} \\ \text { 15 } & 1.536092 & 0.026_{2} \\ \text { ge of replications } & 1.536122 & \text { Third group } \\ \text { ge of replications } & & \end{array}\right\}$

accuracy with a low pressure mercury discharge lamp placed before the entrance slit of the monochromator. The following wavelengths were used for calibration: $3650.2 \AA$; $4046.6 \AA$; $4077.8 \AA$; 4339.2 $\AA ; 4347.5 \AA ; 4358.4 \AA$; $4916.0 \AA ; 5460.7 \AA ; 5769.6 \AA$; and $5790.7 \AA$. If additional reference wavelengths are needed, a Cd-Hg or a He-discharge lamp could be used for calibration. The wavelength counter was then checked using the procedure recommended by Gibson [2], and a slit of $0.1 \mathrm{~mm}$ which is equivalent to an effective spectral bandpass of $0.08 \mathrm{~nm}$. The deviation of the wavelength counter from the true value was found to be less than $\pm 0.1 \mathrm{~nm}$; hence no wavelength correction was applied to the measurements discussed here.

\section{Stray Radiation}

Tests were made to determine the stray radiant energy (SRE) in the monochromator proper, as well as in the photometric arrangement. The measurement of stray radiation in the monochromator, that is, the radiation energy at wavelengths different from those of the nominal spectral bandpass transmitted through the instrument, is not easy or infallible. A detailed discussion of this instrumental parameter was given in an ASTM Tentative Method [35] and the pro- cedure recommended in this work was used to determine SRE in the blue and yellow spectral range. In this procedure, a solution of methylene blue, which has a strong absorption in the range from $\lambda 600$ to $660 \mathrm{~nm}$ is used. The SRE using a slit of $1 \mathrm{~mm}(0.8 \mathrm{~nm})$ was equal to or less than five parts in $10^{5}$.

The SRE generated inside the photometric system is defined as the radiant energy which falls on the photosensitive detector without passing through the absorbing sample. This SRE is usually produced by reflections and scattering of radiations on the optical and mechanical parts located between the exit slit of the monochromator and the integrating sphere. The measurements were performed using a slit of $1 \mathrm{~mm}$ by placing a front surface mirror at the sample position, which reflects to the instrument all radiations received from the exit slit imaged at the mirror surface. The size of this image was about $8 \mathrm{~mm}$ high and $1 \mathrm{~mm}$ wide. In this way, a maximum SRE was generated in the spectrophotometer. The measurements were then performed at $\lambda 577.3 \mathrm{~nm}$, using a radiation flux intensity five times greater than that used in routine transmittance measurements, by determining the dark current of the photomultiplier with the shutter in the closed position at the integration sphere. An average dark current of $0.040 \mathrm{mV}$ was observed. The mirror was then placed at the sample position, the shutter 
TABLE 4. Stability of the current-to-voltage converter, the photomultiplier tube at $850 \mathrm{~V}$, and the tungsten ribbon filament lamp

\begin{tabular}{|c|c|c|}
\hline Replication & $\begin{array}{l}\text { Average of } 50 \text { individual } \\
\text { measurements; volts }\end{array}$ & $\begin{array}{c}\text { Percent standard } \\
\text { deviation }\end{array}$ \\
\hline 1 & 2.002395 & $0.038_{0}$ \\
\hline 2 & 2.001356 & $0.022_{6}$ \\
\hline 3 & 2.002145 & $0.024_{7}$ \\
\hline 4 & 2.000975 & $0.026_{2}$ \\
\hline 5 & 2.001944 & $0.020_{7}$ \\
\hline 6 & 2.000925 & $0.028_{1}$ \\
\hline 7 & 2.001832 & $0.026_{1}$ \\
\hline 8 & 2.000825 & $0.023_{5}$ \\
\hline 9 & 2.001551 & $0.026_{3}$ \\
\hline 10 & 2.000960 & $0.021_{2}$ \\
\hline 11 & 2.001739 & $0.023_{1}$ \\
\hline 12 & 2.000851 & $0.024_{4}$ \\
\hline 13 & 2.001729 & $0.028_{2}$ \\
\hline 14 & 2.000825 & $0.023_{0}$ \\
\hline 15 & 2.001557 & $0.024_{4}$ \\
\hline Average of replications & 2.001441 & \\
\hline $\begin{array}{l}\text { Percent standard } \\
\text { deviation }\end{array}$ & 0.026 & First group \\
\hline Average of replications & 2.001517 & \\
\hline $\begin{array}{l}\text { Percent standard } \\
\text { deviation }\end{array}$ & 0.012 & Second group \\
\hline Average of replications & 2.000826 & \\
\hline $\begin{array}{l}\text { Percent standard } \\
\text { deviation }\end{array}$ & 0.025 & Third group \\
\hline $\begin{array}{l}\text { Average of replications } \\
\text { Percent standard } \\
\text { deviation }\end{array}$ & 2.001268 & Fourth group \\
\hline
\end{tabular}

TABLE 5. Reproducibility of transmittance measurements on seven Schott NG-4 glass filters No. 2; 4; 6; 8; 10; 12 ; and 14

\begin{tabular}{|c|c|c|c|c|c|c|c|}
\hline \multirow{2}{*}{ Replication No. } & \multicolumn{7}{|c|}{ Percent transmittance } \\
\hline & 2 & 4 & 6 & 8 & 10 & 12 & 14 \\
\hline 1 & 33.327 & 21.711 & 12.236 & 50.990 & 33.377 & 20.906 & 13.473 \\
\hline 2 & 33.325 & 21.710 & 12.237 & 50.983 & 33.377 & 20.903 & 13.471 \\
\hline 3 & 33.321 & 21.711 & 12.241 & 50.992 & 33.383 & 20.900 & 13.474 \\
\hline 4 & 33.320 & 21.708 & 12.240 & 50.988 & 33.375 & 20.901 & 13.470 \\
\hline 5 & 33.323 & 21.710 & 12.239 & 50.983 & 33.379 & 20.901 & 13.474 \\
\hline 6 & 33.325 & 21.710 & 12.238 & 50.986 & 33.377 & 20.904 & 13.470 \\
\hline Average & 33.32 & 21.710 & 12.238 & 50.987 & 33.378 & 20.902 & 13.472 \\
\hline Percent $\sigma$ & 0.0080 & 0.0051 & 0.0150 & 0.0072 & 0.0083 & 0.0108 & 0.0141 \\
\hline Average percent $\sigma$ & & & & 0.010 & & & \\
\hline
\end{tabular}

was opened and measurements were made again. The average value found was $0.037 \mathrm{mV}$. This indicated that no SRE could be detected under the experimental circumstances.

\section{Linearity Control}

The single-beam static optical system described in this work permits the unequivocal use of the radiation 
addition principle by means of the double-aperture method for determining departure from linearity of the entire optical, photometric, and electronic system, and thus of the photometric accuracy of transmittance measurements.

The double-aperture and its positioning on the optical bench was described earlier. Its use will now be illustrated, and follows the procedure developed and used at the National Physical Laboratory.

Since the linearity of photometric data for a given photomultiplier tube depends on the anode voltage, the values at the current-to-voltage converter, and the ambient temperature, all measurements were made using identical experimental conditions. These same conditions were maintained when transmittance measurements were performed. Since the linearity is, within 1 part in $10^{4}$, not usually a function of wavelength [36], all measurements were performed at $\lambda$ $565.0 \mathrm{~nm}$. A recent study of this parameter at NBS by Mielenz and Eckerle indicates that there may be a relation between wavelength and linearity at the level of 1 part in $10^{5}$ [38].

The intensity of the radiation flux produced by the tungsten ribbon lamp was attenuated with the circular neutral wedge until a photocurrent equivalent to $2.0020 \mathrm{~V}$ was obtained when both apertures, A and $\mathrm{B}$, were open. A setting of $850 \mathrm{~V}$ was used at the photomultiplier tube with a $30 \mathrm{M} \Omega$ resistor at the currentto-voltage converter. Fifty individual DVM readings were taken and the average value for $(A+B)$ was printed. Aperture $B$ was then closed, and 50 DVM readings were taken. The average value for aperture $A$ was printed. The average value for aperture $B$ was then obtained in a similar manner by closing aperture $A$ and opening aperture $B$. This sequence was repeated three times, ending with an $(A+B)$ value.

Identical measurements were made over a range of attenuation corresponding to 4 cascaded steps of 2 to $l$ as illustrated in the actual example which follows:

\begin{tabular}{|c|c|c|c|}
\hline \multirow[t]{5}{*}{ Step 1} & $(A+B)$ & $A$ & $B$ \\
\hline & $2.0014_{7}$ & $1.0159_{6}$ & $0.9864_{1}$ \\
\hline & $2.0015_{6}$ & 1.01599 & $0.9864_{0}$ \\
\hline & $2.0020_{6}$ & $\underline{1.0160_{9}}$ & $\underline{0.9862_{5}}$ \\
\hline & $\underline{2.002 l_{1}}$ & $\overline{1.01598}$ & $\overline{0.98635}=2.00233$ \\
\hline Av. & $\overline{2.00181}$ & & \\
\hline $\begin{array}{l}\text { Diff. } \\
\% \text { Corr. }\end{array}$ & $\begin{array}{l}2.00233 \\
=-0.02\end{array}$ & $.00181=$ & 0.00052 \\
\hline
\end{tabular}

$\begin{array}{lccc}\text { Step 2 } & (A+B) & A & B \\ & 1.0004_{9} & 0.5102_{0} & 0.4910_{8} \\ & 1.0007_{8} & 0.5099_{6} & 0.4909_{1} \\ & 1.0006_{6} & \underline{0.5100_{4}} & \underline{0.4911_{5}} \\ & \frac{1.0009_{0}}{0.51007}+ & 0.49105=1.00112 \\ \text { Av. } & 1.00071 & \\ \text { Diff. } & 1.00112-1.00071=+0.00041 \\ \text { \% Corr. } & =-0.041\end{array}$

$\begin{array}{cccc}\text { Step } 3 & (A+B) & A & B \\ & 0.5006_{2} & 0.2565_{7} & 0.2443_{0}\end{array}$

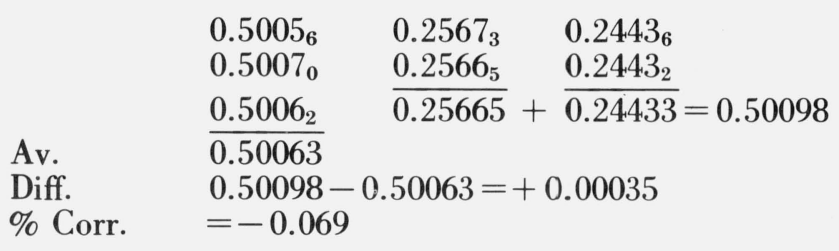

Step 4 $(A+B) \quad A \quad B$ $\begin{array}{lll}0.2502_{0} & 0.1287_{2} & 0.1217_{5}\end{array}$ $\begin{array}{lll}0.2502_{8} & 0.1285_{6} & 0.1216_{8}\end{array}$ \begin{tabular}{lll}
$0.2501_{9}$ & $0.1285_{4}$ & $0.1216_{6}$ \\
\hline
\end{tabular}

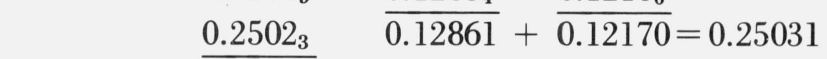

Av. $\quad \overline{0.25023}$

Diff. $\quad 0.25031-0.25023=+0.00008$

$\%$ Corr. $=-0.031$

The correction curve is established from these data by plotting voltages on the abscissa and the corresponding additive correction value on the ordinate. 'These are tabulated below and illustrated in figure 16.

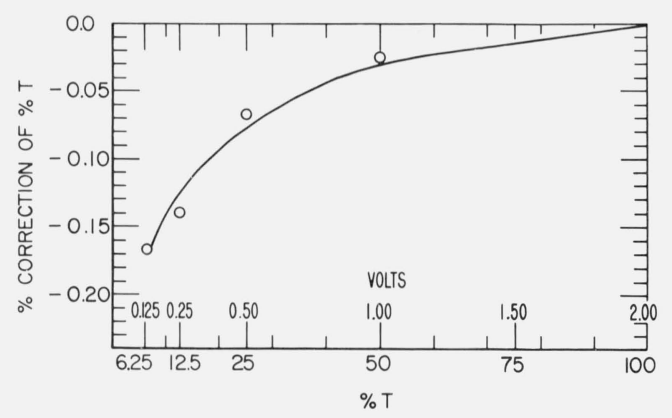

FIGURE 16. Linearity correction curve.

$\begin{array}{lcl}\text { Voltage } & \% T & \% \text { Correction of } \% T \\ & & \\ 2.00 & 100 & 0.0 \\ 1.00 & 50 & 0.026 \\ 0.50 & 25 & 0.067 \\ 0.25 & 12.5 & 0.14 \\ 0.125 & 6.25 & 0.167\end{array}$

When transmittance measurements are performed, the $I_{0}$ reading is initially set with the circular neutral wedge to a value near $2.0020 \mathrm{~V}$. The $I$ value is then measured. If the initial $I_{0}=2.00214 \mathrm{~V}$ and final $I_{0}=2.0022_{8} \mathrm{~V}$ and $I=0.54220 \mathrm{~V}$, then percent $T$ is:

$$
\frac{0.54220}{\frac{2.00214+2.00228}{2}} \times 100=27.081
$$

which is the noncorrected value. To correct this value, one takes from the ordinate of figure 16 the value corresponding to 0.54220 on the abscissa which, in this case, is 0.072 . The corrected percent $T$ value is then:

$$
27.081-\left(\frac{27.081 \times 0.072}{100}\right)=27.061 \text {. }
$$


Mielenz and Eckerle have studied recently the double aperture method for testing photometric linearity, and have used a curve-fitting procedure for finding the nonlinearity correction rather than the method described earlier (38).

\section{Sample Position}

A series of measurements were performed to determine the magnitude of error which could occur when the sample is oriented with its entrance face at an angle to the incoming radiation beam. The single sample holder provided with the rotating table, as described in section II, paragraph c, was used. Transmittance measurements were performed by producing the image of the exit slit of the monochromator at the entrance face of the sample (aperture $f: 10$ ). The data are shown in table 6 . The consequence of this condition on transmittance measurements is discussed by Mielenz in this Journal.
TABLE 6. Percent transmittance $(\% T)$, measured on three neutral glass filters $1.0 ; 1.5$; and $2.0 \mathrm{~mm}$ thick at $\lambda=440 \mathrm{~nm}$, at three angles of incidence

$\begin{array}{lccc}\begin{array}{l}\text { Angle of } \\ \text { incidence }\end{array} & \begin{array}{c}\text { Filter } \\ 1.0 \mathrm{~mm}\end{array} & \begin{array}{c}\text { Filter } \\ 1.5 \mathrm{~mm}\end{array} & \begin{array}{c}\text { Filter } \\ 2.0 \mathrm{~mm}\end{array} \\ \text { Normal incidence } & 32.91_{5} & 19.83_{8} & 11.60_{6} \\ 1^{\circ} & 32.89_{9} & 19.83_{3} & 11.60_{4} \\ 2^{\circ} & 32.89_{7} & 19.81_{9} & 11.59_{9} \\ 3^{\circ} & 32.88_{1} & 19.81_{2} & 11.58_{9}\end{array}$

Similar measurements were made to determine the identity of positions on the seven-sample automatic changer described in section II, paragraph c. For this experiment, seven neutral glass filters A; B; C; $\mathrm{D} ; \mathrm{E} ; \mathrm{F}$; and $\mathrm{G}$ were used and were positioned in holders $2 ; 4 ; 6 ; 8 ; 10 ; 12$; and 14 in three different arrangements as described by Garfinkel, Mann and Youden [39].

TABLE 7. Evaluation of the identity of the seven stations of the automatic sample changer

Percent Transmittance $(\% T)$ at station number (St. No.) $2 ; 4 ; 6 ; 8 ; 10 ; 12$; and

14 for filters A, B, C, D, E, F, and G at $\lambda=465.0 \mathrm{~nm}$

\begin{tabular}{|c|c|c|c|c|c|c|c|c|}
\hline Run & No. & A & B & C & D & $\mathrm{E}$ & F & G \\
\hline \multirow{3}{*}{ I } & $\% T$ & 27.08 & 16.44 & 46.39 & 26.12 & .15.22 & 37.34 & 23.23 \\
\hline & St. & & & & & & & \\
\hline & No. & 2 & 4 & 6 & 8 & 10 & $12^{\prime}$ & 14 \\
\hline \multirow{3}{*}{ II } & $\% T$ & 27.07 & 16.40 & 46.39 & 26.11 & 15.21 & 37.34 & 23.23 \\
\hline & St. & & & & & & & \\
\hline & No. & 14 & 2 & 4 & 6 & 8 & 10 & 12 \\
\hline \multirow{3}{*}{ III } & $\% T$ & 27.08 & 16.43 & 46.39 & 26.11 & 15.21 & 37.33 & 23.23 \\
\hline & St. & & & & & & & \\
\hline & No. & 10 & 12 & 14 & 2 & 4 & 6 & 8 \\
\hline
\end{tabular}

Transmittance measurements were then performed on all filters for the three different arrangements and the results are given in table 7 . From these data it can be concluded that the seven stations are interchangeable and will produce measurements which will not differ by more than one part in one thousand.

\section{Influence of Polarized Radiations on Transmittance Measurements}

This effect was determined by measuring the transmittance of a Schott NG-4 neutral glass filter at four wavelengths using radiations emerging from the predisperser-monochromator unit, and by projecting the image of the exit slit $(8$ by $0.5 \mathrm{~mm})$ at the entrance face of the filter with a convergent beam geometry corresponding to an $f: 10$ opening. The glass filter was checked prior to measurements with a polariscope for freedom of internal tensions. Column one of table 8 shows the results obtained when transmittance measurements were made using the radiations produced by the spectrophotometer. Column two shows the results

obtained when a polarizing sheet, with the vibration plane horizontal, was placed in front of the glass filter. The measurements obtained with the vibration plane in vertical position, are given in column three.

These measurements show that polarized radiations san affect transmittance measurements of solid glass filters when noncollimated beam geometry is used. This effect is predicted by the Fresnel equations mentioned in the introduction and should disappear when collimated radiations are used (1, pg. 100).

\section{Comparison of Transmittance Measurements}

Two sets of solid filters were used in a comparative test to determine the reproducibility of transmittance measurements between two laboratories. One set was made from three neutral glass Schott NG-4 filters having nominal percent transmittances of $10 ; 20$; and 30 . The second set was made as described elsewhere [4]. Three evaporated metal (Inconel) on fused quartz (nonfluorescent) plates having nominal percent 
TABLE 8. Effect of polarization on percent transmittance (\%T) measured at four wavelengths on a Schott NG-4 glass filter

\begin{tabular}{|c|c|c|c|c|}
\hline \multirow[b]{2}{*}{$\begin{array}{l}\text { Wavelength } \\
\mathrm{nm}\end{array}$} & \multicolumn{3}{|c|}{$\% T$} & \multirow[b]{2}{*}{$\begin{array}{c}\% \text { Difference } \\
\% T_{1}-\% T_{3}\end{array}$} \\
\hline & $\begin{array}{c}\text { Produced by } \\
\text { spectro- } \\
\text { photometer }\end{array}$ & $\begin{array}{c}\text { Polarizer, } \\
\text { plane of } \\
\text { vibration } \\
\text { horizontal }\end{array}$ & $\begin{array}{c}\text { Polarizer, } \\
\text { plane of } \\
\text { vibration } \\
\text { vertical }\end{array}$ & \\
\hline & 1 & 2 & 3 & \\
\hline 440.0 & $19.81_{8}$ & $19.80_{0}$ & $19.78_{8}$ & -0.15 \\
\hline 465.0 & $22.59_{7}$ & $22.60_{0}$ & $22.56_{9}$ & -0.12 \\
\hline 590.0 & $19.17_{8}$ & $19.17_{0}$ & $19.09_{9}$ & -0.41 \\
\hline 635.0 & $20.61_{1}$ & $20.60_{2}$ & $20.54_{7}$ & -0.31 \\
\hline
\end{tabular}

transmittances of $25 ; 50$; and 75 were used. The transmittance measurements were performed on two sets of filters at the National Physical Laboratory (NPL) in England using their high accuracy spectrophotometer, and at NBS on the instrument described in this paper. The measurements at NBS were carried out before and after the measurements at NPL. All measurements were made with noncollimated convergent beam geometry. A rectangular surface of the filter about $3 \mathrm{~mm}$ by $8 \mathrm{~mm}$ was used at NPL and the beam was only slightly convergent. At NBS an area about $8 \mathrm{~mm}$ by $0.5 \mathrm{~mm}$ was used for the transmittance measurements.

The results given in table 9 indicate that an average difference of -0.19 percent of the values was obtained between the measurements carried out at NPL and at NBS. An average difference of -0.30 percent of the value was found when similar measurements were performed on the inconel-on-quartz filters, as shown in table 10 .

\section{Standard Reference Materials for Spectrophotometry}

The need for providing means and materials $t$, check the proper functioning of a spectrophotometer was discussed in some detail in previous publications [3, 4]. At that time it was established that the accuracy of the photometric scale is a critical and most demanding parameter in spectrophotometry. Hence, particular attention was given to a number of ways for checking this parameter. Investigations showed that solid colored glass filters, exhibiting optical neutrality over the spectral range from $400.0 \mathrm{~nm}$ to $700.0 \mathrm{~nm}$, would constitute an acceptable Standard Reference Material (SRM). From the various colored glass

TABLE 9. Comparison between the percent transmittances $(\% T)$ measured on three Schott NG-4 glass filters at NPL and NBS

$\begin{array}{cccccc}\begin{array}{c}\text { Wavelength } \\ \text { nm }\end{array} & \begin{array}{c}\text { NBS, } \% T \\ \text { March 12, } \\ 1971\end{array} & \begin{array}{c}\text { NBS, } \% T \\ \text { May 18, } \\ 1971\end{array} & \begin{array}{c}\text { NBS, \% } T \\ \text { average }\end{array} & \begin{array}{c}\text { NPL, \% } T \\ \text { February } \\ 1971\end{array} & \begin{array}{c}\text { \% Diff. } \\ \text { NBS to NPL }\end{array} \\ 440.0 & 12.92 & 12.91 & 12.91_{5} & 12.93 & -0.11 \\ 465.0 & 14.96_{5} & 14.98 & 14.97_{3} & 15.01 & -0.25 \\ 590.0 & 11.70 & 11.64 & 11.67 & 11.67 & 0.0 \\ 635.0 & 12.72 & 12.68 & 12.70 & 12.72 & -0.16 \\ & & & & & \\ 440.0 & 19.62_{5} & 19.58 & 19.60_{3} & 19.62 & -0.09 \\ 465.0 & 22.38_{5} & 22.35 & 22.36_{7} & 22.43 & -0.28 \\ 590.0 & 19.06 & 18.95 & 19.00_{5} & 19.01 & -0.03 \\ 635.0 & 20.45_{5} & 20.37 & 20.41_{3} & 20.47 & -0.23 \\ & & & & & \\ 440.0 & 32.89 & 32.86 & 32.87_{5} & 32.98 & -0.32 \\ 465.0 & 35.52 & 35.54 & 35.53 & 35.66 & -0.36 \\ 590.0 & 31.16_{5} & 31.10 & 31.13_{3} & 31.21 & -0.25 \\ 635.0 & 32.56_{5} & 32.52 & 32.54_{3} & 32.62 & -0.24\end{array}$

Average difference between NBS and NPL percent $T$ values $=-0.19$ percent.

filters available, Schott NG-4 "neutral glass" was selected, prepared and characterized. It is now offered by NBS as a means to check the photometric scale of spectrophotometers. 
TABLE 10. Comparison between the percent transmittances $(\% T)$ measured on three inconel-on-silica filters at NPL and NBS

\begin{tabular}{|c|c|c|c|c|c|}
\hline \multirow{2}{*}{$\begin{array}{c}\text { Wavelength } \\
\mathrm{nm}\end{array}$} & \multicolumn{2}{|c|}{ NBS, $\% T$} & \multirow{2}{*}{$\begin{array}{c}\text { NBS, } \% T \\
\text { average }\end{array}$} & \multirow[b]{2}{*}{ NPL, $\% T$} & \multirow{2}{*}{$\begin{array}{c}\% \text { Diff. } \\
\text { NBS to NPL }\end{array}$} \\
\hline & 1 & 2 & & & \\
\hline 450.0 & 24.87 & 24.88 & $24.87_{5}$ & 24.93 & -0.18 \\
\hline 550.0 & 23.78 & 23.82 & 23.80 & 23.86 & -0.25 \\
\hline 650.0 & 23.38 & 23.39 & $23.38_{5}$ & 23.46 & -0.32 \\
\hline 450.0 & 49.35 & 49.33 & 49.34 & 49.56 & $-0.44^{*}$ \\
\hline 550.0 & 47.60 & 47.60 & 47.60 & 47.81 & -0.44 \\
\hline 650.0 & 46.85 & 46.85 & 46.85 & 47.14 & -0.64 \\
\hline 450.0 & 72.17 & 72.20 & $72.18_{5}$ & 72.30 & -0.16 \\
\hline 550.0 & 72.05 & 72.11 & 72.08 & 72.20 & -0.17 \\
\hline 650.0 & 72.20 & 72.34 & 72.27 & 72.33 & -0.08 \\
\hline
\end{tabular}

Average difference between NBS and NPL percent $T$ values $=-0.30$ percent.

\begin{abstract}
*This filter had a flaw in the form of a crack which was sometimes visible and other times invisible. The larger differences found in the measurements of this filter may be due to this flaw.
\end{abstract}

SRM 930, developed in the Analytical Chemistry Division and available since March 1971 consists of three glass filters. Each filter bears an identification number, and the upper left corner has been removed to indicate correct orientation in the metal holder (fig. 17).

The transmittance measurements were made with the high accuracy spectrophotometer described in this paper, and are certified with an uncertainty of \pm 0.5 percent of the value. This uncertainty is the sum of the random errors of \pm 0.1 percent (2SD limit) and of estimated biases which are \pm 0.4 percent. These biases are due to possible systematic errors originating principally from the inherent inhomogeneity and instability of the glass as well as from positioning of the filter. Measurements were made at $24{ }^{\circ} \mathrm{C}$, and variations within several degrees Celsius of this temperature will not significantly affect the calibration of the filters. The neutral NG-4 glass for the filters was provided by Schott of Mainz, Germany and is designated as "Jena Colored and Filter Glass." Nominal transmittance for a filter $1.5 \mathrm{~mm}$ thick is 20 percent at $400.0 \mathrm{~nm}$ wavelength and 32 percent at $700.0 \mathrm{~nm}$ wavelength. Between these limits the transmittance varies in a monotonic manner.

The filter is held in a frame and the size and shape of the filters and frames were selected, for practical considerations, to conform to the dimensions of the standardized cuvettes for which holders are supplied in most conventional spectrophotometers. The filters are approximately $1.0,1.5$, and $2.0 \mathrm{~mm}$ thick. Corresponding to these thicknesses are nominal transmittances of 30,20 , and 10 percent, respectively. These thicknesses were selected to provide a means for calibrating the photometric scale at three different levels.
The effective spectral bandpasses used to determine the certified values were equal to or smaller than $2.2 \mathrm{~nm}$ at $440.0 \mathrm{~nm} ; 2.7 \mathrm{~nm}$ at $465.0 \mathrm{~nm} ; 5.4 \mathrm{~nm}$ at $590.0 \mathrm{~nm}$; and $6.0 \mathrm{~nm}$ at $635.0 \mathrm{~nm}$. The transmittance measurements are made by producing the image of the slit (about $8 \mathrm{~mm}$ by $0.5 \mathrm{~mm}$ ) using a convergent beam geometry with an opening of $\mathrm{f}: 10$ corresponding to an angle of $7^{\circ}$ to $8^{\circ}$ in the middle of the entrance face of the filter. This beam geometry was used to reproduce the average experimental conditions found in most of the conventional spectrophotometers available today. Prior to the certification, each filter is examined for surface defects and thoroughly cleaned. If, through handling, the surface of the filter becomes contaminated, it may be cleaned with a small soft brush attached to a rubber tube connected to a vacuum source [40]. If contamination results from fingerprints, they must be removed before making measurements. This may be accomplished by removing the filter from its holder, breathing lightly on it, and rubbing the surface gently with optical lens tissue. The clean filter is then properly positioned in its holder. To remove and replace the filter in the holder, the spring-loaded plate should be lifted with care to prevent damage to the filter. As little handling as possible is recommended. SRM 930 should be used according to the directions on the certificate; consult the manufacturer of the instrument if differences are obtained that exceed those specified by the manufacturer.

Under no circumstances should other cleaning procedures which make use of detergent solutions, organic solvents, etc. be applied.

When a filter has become contaminated beyond cleaning by the procedure described in the certificate, it should be forwarded to NBS. After proper cleaning, the filters will be checked and, if needed, 


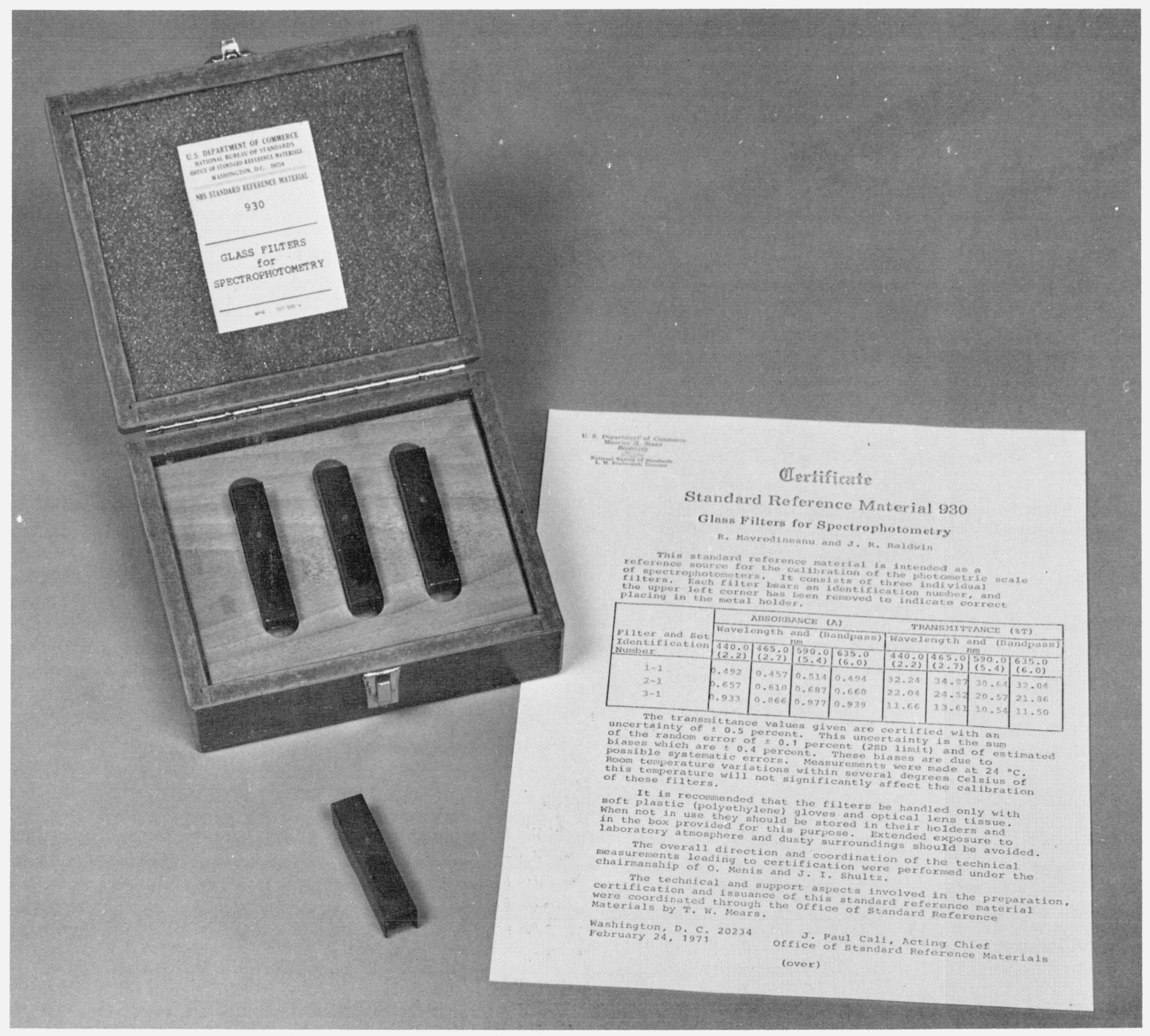

FIGURE 17. NBS Standard Reference Material 930 and calibration certificate.

recalibrated using the high accuracy spectrophotometer described in this work.

It was already stated that the accuracy of photometric scales defines only one of the parameters required for obtaining accurate transmittance values and molar absorptivities. Other factors must also be established. These are wavelength accuracy, adequate spectral bandpass, stray light, cell parameters (when solutions are measured), fluorescence, polarization, reflection, and temperature coefficient. Some of these variables were discussed in NBS Technical Notes 544 and 584 and are also examined in this paper.

The transmittance data given in the certificate which accompanies each SRM 930 depend not only on the intrinsic properties of the glass and the experimental measurement conditions, but on the surface state of the glass. This parameter varies with time and exposure conditions. When glass is exposed to normal room atmosphere and temperature, its surface is corroded to an extent depending on the composition, time of exposure, concentration, temperature and nature of the glass surface acting agents. This action produces a change in the reflecting and transmitting properties of the material [41]. For instance, a well-known phenomenon called "blooming" of the glass is due to the formation of an $\mathrm{SiO}$ layer at the surface of the glass. This layer, which increases the transmittance, acts as an antireflection coating. The speed with which such a layer is formed varies with the composition of the glass, the atmosphere and time. Generally speaking, several years are needed for a fresh surface to reach equilibrium. This, and similar 
phenomena are presently being studied, along with means to stabilize the surface state of glass filters. Until more information is acquired in this field, we recommend that the colored glass filters issued as SRM 930 be rechecked annually to determine whether any physicochemical changes, which might affect the transmittance values, have occurred.

Another important factor is the need for defining and producing a clean glass surface. Until now the final cleaning of the NG-4 filters was made with redistilled ethyl alcohol and pure water (thermally distilled and deionized). Other cleaning procedures are under consideration. The use of isopropyl alcohol in vapor or liquid form associated with mild ultrasonic action is being investigated [41].

The transmittance characteristics of the SRM 930 limit the use of this material to the visible region of the spectrum from about $400 \mathrm{~nm}$ to the near infrared. Since the ultraviolet region, from about $200 \mathrm{~nm}$ is also important to the analyst who uses spectrophotometric methods, exploratory work is underway to select and certify solid material for checking the photometric scale in this spectral region. Optical filters exhibiting small transmittance-wavelength dependence in the spectral range $200 \mathrm{~nm}$ to near infrared can be obtained by evaporating thin semitransparent layer of a metal on a suitable transparent substrate $[42,4]$, and such filters have been considered in this work. The metals selected were inconel and chromium which exhibit adequate transmission characteristics and good adhesion to the substrate. The substrate was nonfluorescent fused quartz. A series of filters were prepared by the optical shop at NBS according to the following specifications: a number of nonfluorescent optical quality fused quartz plates, $10 \mathrm{~mm} \times 25 \mathrm{~mm}$ and $1 \mathrm{~mm}$ thick, were cut and polished, Inconel or chromium metal was evaporated on the surface to produce nominal transmittances of 25,50 , and 75 percent. The surface bearing the evaporated metal was coated with a layer of optical cement which was transparent to the visible and ultraviolet radiations down to 230 $\mathrm{nm}$. A clear plate of the same material was used to cover and protect the evaporated metal layer.

The filter assembly was then marked at one corner to insure its proper positioning and the finished filter was placed in a metal holder of conventional size (approximate o.d. $13 \times 13 \times 57 \mathrm{~mm}$ ) fitting the cuvette holder found in most spectrophotometers. The metal holder was also marked at one side to permit positioning of the filter in a reproducible manner.

In addition to the evaporated metal filters, a number of units were prepared using only the clear uncoated fused quartz plates and assembled with the same optical cement. When desired, these clear filter assemblies could be used as reference samples in the blank compartment.

Before submitting the evaporated metal filters to transmittance measurements, a study was made of the effect of radiations on their transmittances. A filter was exposed to an accelerated test in which radiations had the same spectral distribution as the fluorescent lighting of the laboratory, except that they were 1000 times more intense. The filter was exposed for an equivalent of 36,000 hours of continuous irradiation. This test was made on a radiation accelerator made available by the Building Research Division of NBS. The percent transmittance was measured before and after the exposure and gave the following results:

Transmittance, percent

$\begin{array}{lrrrr}\text { Wavelength, nm } & 250 & 380 & 500 & 650 \\ \text { Before exposure } & 44.48 & 51.35 & 48.90 & 47.41 \\ \text { After exposure } & 44.11 & 51.34 & 48.92 & 47.47\end{array}$

The relative standard deviation for a single determination of these measurements was 0.01 percent. As can be seen, the only significant relative change in transmittance of about 0.84 percent of the value occurred at $250 \mathrm{~nm}$.

Several sets of these filters were calibrated at five selected wavelengths, $250 \mathrm{~nm} ; 350 \mathrm{~nm} ; 450 \mathrm{~nm} ; 550$ $\mathrm{nm}$; and $650 \mathrm{~nm}$, using the cleaning and measuring procedures outlined for Schott NG-4 colored glass neutral filters. The results indicated that the reproducibility of transmittance measurements is good (percent standard deviation 0.009 to 0.024 ) and is comparable to those obtained for the colored glass filters at all wavelengths except $250 \mathrm{~nm}$. From the experimental data, it is evident that the transmittance of the evaporated metal filter at $250 \mathrm{~nm}$ is critical and, at present, no satisfactory explanation for this phenomenon can be given. A limitation of the evaporated metal filters is that they attenuate the intensity of radiation by reflecting a part of it, rather than absorbing. This can produce, in certain circumstances, undesirable stray light in the instrument and make the transmission measurements dependent on the geometry of the optical beam. However, since these filters are closer to optical neutrality than the colored glass filters, and since they can be used in the ultraviolet region as well, they were included in this work.

This limitation was apparent from the data obtained in a cooperative study conducted at C. Zeiss by A. Reule using conventional spectrophotometers. On the other hand, a similar comparative test, made on the same filters by F. J. J. Clarke at NPL has produced the results presented in table 10 . One can observe that, in spite of the limitations mentioned above, an agreement within -0.30 percent of the value was obtained between NBS and NPL measurements at the indicated wavelength.

Further studies will be needed to assess unambiguously the transmittance characteristics of evaporated metal-on-quartz filters, with or without a protective quartz plate, and to assess their suitability as Standard Reference Materials to check the photometric scale of spectrophotometers in the ultraviolet and visible part of the spectrum. 


\section{Addendum}

The identification of commercial instruments and products, is given in the Addendum only to permit reproduction of the work described in this paper. In no instances does such identification imply recommendation or endorsement by the National Bureau of Standards, nor does it imply that the particular equipment or product is necessarily the best available for the purpose.

Radiation source for visible-Microscope lamps, type 18A/T10/1P-6V: General Electric Co., Lamp Division, Nela Park, Cleveland, Ohio 44112. For ultraviolet: Atlas single coil halogen (Bromine) lamp, type P1/8, 30V, 250W: GTE Sylvania, Inc., 6610 Electronic Drive, Springfield, Virginia 22151.

Power supply for microscope lamp, Kepco, Model JQE 15-50-M-VP: Kepco, Inc., 131-38 Sanford Avenue, Flushing, New York 11352. For tungstenhalogen single filament lamp: same manufacturer, Model JQE-36-30 Mt-VP.

Potentiometer: Leeds and Northrup Model K3 with null meter and power supply. Resistors: Leeds and Northrup 0.1, $50 \mathrm{~A}$ and $0.01,100 \mathrm{~A}$ : Leeds and Northrup, Sumneytown Pike, North Wales, Pa. 19454.

Nonfluorescent fused silica: Dynasil Corporation of America, Berlin, New Jersey 08009.

Neutral Density Attenuator and $\mathrm{BaSO}_{4}$ white paint: Eastman Kodak Co., Special Products Sales, Kodak Apparatus Division, Elmgrove Plant, Rochester, New York 14650.

Monochromator with predisperser: McPherson Instrument Corp., 530 Main Street, Acton, Massachusetts 01720 .

Optical benches with carriers and $x-y$ sample holder with micrometer control: Gaertner Scientific Corp., 1201 Wrightwood Ave., Chicago, Illinois 60614.

Lens holders: Ardel Instrument Co., Inc., P. O. Box 992, Jamaica, New York 11431.

Ball bushing and rails: Thompson Industries, Inc., Manhasset, New York 11030.

Pneumatic cylinders and accessories: Clippard Instrument Laboratory, Inc., Cincinnati, Ohio 45239.

Rotating table: Ealing Optics Division, 2225 Massachusetts Avenue, Cambridge, Massachusetts 02140.

Thermostating holders for glass cells and glass filters: Cary Instruments, 2724 South Peck Road, Monrovia, California 91016.

Pneumatic ratchet system: Allenair Corp., P. O. Box 350, 255 East 2nd Street, Mineola, New York 11501.

Black paint-Nextel 101-c 10 Black: Reflective Products Division 3M, 2501 Hudson Road, St. Paul, Minnesota 55101.

Photomultiplier tube EMI-9558QA: Gencom Division, 80 Express Street, Plainview, New York 11803.

Power supply for photomultiplier tube: Model 415B and digital voltmeter 8400A: John Fluke Manufacturing Co., P.O. 7428, Seattle, Washington 98133.
Thermal insulation: Photoshroud, Shumway Optical Instruments Corp., 2118 Beechgrove Place, Utica, New York 13501.

Vibration isolation table: Lansing Research Co., 705 Willow Avenue, Ithaca, New York 14850.

Low power laser; Model $195 \mathrm{cw}$ gas laser, output power 2 mw: Optics Technology, Inc., 901 California Avenue, Palo Alto, California 94304.

Tritium activated fluorescent source, Beta light Marker HM-110: Canrad Precision Industries, Inc.. 630 Fifth Avenue, New York, New York 10020.

Colored glass neutral filters, Schott NG-4: FishSchurmann Corp., 70 Portman Road, New Rochelle, New York 10802.

Spectral lamp: Oriel Optics Corp., 1 Market Street, Stamford, Connecticut 06902.

Polarization filters: Polaroid Corp., 119 Windsor Street, Cambridge, Massachusetts 02139.

Computer: $24 \mathrm{~K}$ memory and 16 bit words. EMR computer, Division of Weston Instruments, Inc., Schlumberger Co., 8001 Bloomington Freeway, Minneapolis, Minnesota 55420.

The author gratefully acknowledges the assistance of the following persons, in addition to those already mentioned in the text:

F. J. J. Clarke, for the considerable assistance given through personal discussions on the philosophy and principles of high accuracy spectrophotometry at NPL.

Anne Compton, for advice and help during the experimental work carried-out at the high accuracy spectrophotometer at NPL.

G. E. V. Lambert, for information concerning glass filters (NPL).

K. D. Mielenz (NBS), for constructive discussions on the principles of spectrophotometry and for critically reviewing the manuscript.

W. H. Venable (NBS), for critically reviewing the manuscript.

K. L. Eckerle (NBS), for advice in measuring stray radiations and polarization produced in the monochromator.

C. R. Yokley (NBS), for advice on the radiation stability of incandescent tungsten filament lamps.

W. K. Haller (NBS), for valuable information on the properties of glass surfaces and optical glass filters.

H. H. Ku (NBS), for advice on interpretation of the data discussed in this paper.

NBS Instrument Shop, for constructing the mechanical parts described in this work.

NBS Optical Shop, for grinding the quartz lens used in this work.

D. S. Bright (NBS guest worker), for the programs written at various times during the initial phase of this work.

V..E. Gray (NBS), for assistance in performing the accelerated radiation tests.

H. J. Höfert and A. Reule (C. Zeiss, Oberkochen, Germany), for valuable information on linearity of 
photodetectors and for demonstration of the radiation addition method.

R. J. Carpenter (NBS), for constructive discussions on electronic circuitry and photodetectors.

L. Marzetta (NBS), for advice and assistance in assessing various functioning parameters of photomultiplier tubes.

O. Menis, Section Chief, Analytical Coordination Chemistry (NBS), for approving and encouraging the work reported in this paper.

J. I. Shultz, Assistant Section Chief, Analytical Coordination Chemistry (NBS), for critically reviewing the manuscript.

\section{Referénces}

[1] Kortüm, G., Kolorimetrie-Photometrie und Spektrometrie 464 p. 4 th ed. (Springer-Verlag, 1962)

[2] Gibson, K. S., Spectrophotometry, Nat. Bur. Stand. (U.S.) Circ. 484,48 pages (1949).

[3] Mavrodineanu, R., Spectrophotometry, instrumental develop ment, O. Menis and J. I. Shultz, Eds., Nat. Bur. Stand. (U.S.), Tech. Note 584, pp. 9-21 (1971).

[4] Mavrodineanu, R., Solid materials to check the photometric scale of spectrophotometers, O. Menis and J. I. Shultz, Eds., Nat. Bur. Stand. (U.S.), Tech. Note 544, pp. 6-17 (1970).

[5] Elster, J. and Geitel, H., Un the comparison of light intensities by photoelectric methods, Ann. Physik, Chemie 48, 625-635 (1893).

[6] Elster, J. and Geitel, H., The photoelectric effect on potassium at low light levels, Phys. Ztsch. 13, 468-976 (1912).

[7] Koller, L. R., and Breeding, H. A., Characteristics of photoelectric tubes, General Electric Rev. 31, 476-479 (1928)

[8] Campbell, N. R., The experimental proof of a fundamental photoelectric law, Trans. Opt. Soc. (London) 32, 61-65 (1930-1931).

[9] Fleury, P., An addition method for the precise study of the variation of the current output of a photoelectric cell as a function of the incident luminous flux, Compt. Rend. Acad. Sci. (France) 199, 195-197 (1934).

[10] Preston, J. S., and McDermott, L. H., The illumination response characteristics of vacuum photoelectric cells of the Elster-Geitel Type, Proc. Phys. Soc. (London) 46, 256-272 (1934).

[11] Preston, J. S., and Cuckow, F. W., A photoelectric spectrophotometer of high accuracy, Proc. Phys. Soc. (London) 48, 869-880 (1936)

[12] Buchmüller, F., and König, H., Precision measurements on incandescent lamps using selenium photocells, Assoc. Suisse Electriciens, Bulletin 28, 89-99 (1937).

[13] Atkinson, J. R., Campbell, N. R., Palmer, E. H., and Winch, G. T., The accuracy of rectifier-photoelectric cells, Proc. Phys. Soc. (London) 50, 934-946 (1938).

[14] Barbrow, L., A photometric procedure using barrier-layer photocells, J. Res. Nat. Bur. Stand. (U.S.), 25, 703-710 (1940) RP1348.

[15] Kaiser, H., Photographic-photometric calibration of step filters, Spectrochimica Acta 3, 518-537 (1947-1949).

[16] Harding, H. G. W., Precautions necessary for accurate measurements of optical density standards, Photoelectric Spectrometry Group Bulletin 4, 79-86 (1951).
[17] Kortüm, G., and Maier, H., Dependence of photocurrent and illuminating intensity in photocells and photomultipliers, $\mathrm{Z}$. Naturforschung 8A, 235-245 (1953).

[18] Hansen, G., Check of photometric function of spectrophotom eters, Mikrochimica Acta 1955, 410-415.

[19] Hermann, W., Noise and linearity check on photomultipliers, Z. Naturforschung 12A, 1006-1013 (1957).

[20] Reule, A., Checking the photometer scale of absorption instruments, Zeiss-Mitt. 1, 283-299 (1959).

[21] Hoppmann, H., An instrument for checking the proportionality of physical radiation receivers, Technisch-Wissenschaftliche Abhandlungen Der Osram-Gesellschaft 7, 306-312 (1958).

[22] Gibson, G. L., Hammond, H. K., III, Holford, W. L., and Nimeroff, I., Calibration of photometers, NBS Manuscript, Nov. 1, 1960.

[23] Bischoff, K., Measurement of proportionality of radiation receivers over a large radiation intensity range, Z. Instr. 69 , 143-147 (1961).

[24] Jones, O. C., and Clarke, F. J. J., A new photometric technique using a variable shutter device, Nature 191, 1290 (1961).

[25] Cordle, L. C., and Habell, K. J., Photometry of telescopes and binoculars, National Physical Laboratory, Notes on Applied Science No. 14, 18 pp. (1962).

[26] Sanders, C. L., A photocell linearity tester, Appl. Optics 1, 207-271 (1962)

[27] Nonaka, M., and Kashima, T., Linearity characteristics of multiplier phototubes, Japanese Journal Applied Physics 2, 785791 (1963).

[28] Höfert, H. J., and Loof, H., Calibration of photometric scales of a refléction photometer, Z. Instrumentenkunde 72, 139-143 (1964).

[29] Clarke, F. J. J., Time ratio photometry, Lecture to the Optical Group of the Institute of Physics and the Physical Society (June 9, 1966).

[30] Clarke, F. J. J., High accuracy spectrophotometry of three filters, NPL, Report No. 3042, 14 pp. (Nov. 4, 1968).

[31] Reule, A., Testing spectrophotometer linearity, Appl. Optics 7, 1023-1028 (1968)

[32] Desvignes, F., and Ohnet, J., Characteristics and measurement of properties of radiation receivers, Techniques Philips N.6, $1-18$ (1968).

[33] Kunz, H., Representation of the temperature scale above 1337.58 $\mathrm{K}$ with photoelectric direct current pyrometers, Metrologia $\mathbf{5}$, 88-102 (1969).

[34] Kostkowski, H. J., Personal communication (NBS 1970).

[35] ASTM Tentative Method of Estimating Stray Radiant Energy, ASTM:E 387-69T.

[36] Clarke, F. J. J., Personal communication (NPL, August 1970).

[37] Mielenz, K. D.. and Eckerle, K.. Accuracy of polarization attenuators (to be published), Appl. Optics (1972).

[38] Mielenz, K. D., and Eckerle, K., Spectrophotometer linearity testing using the double-aperture method, Appl. Opt. 11, 2294 (1972).

[39] Garfinkel, S. B., Mann, W. B., and Youden, W. J., Design and statistical procedures for the evaluation of an automatic gamma-ray point-source calibrator, J. Res. Nat. Bur. Stand. (U.S.), 70C (Eng. and Instr.), No 2, 53-63 (1966).

[40] Edisbury, J. R., Practical Hints on Absorption Spectrophotometry (Plenum Press, New York, 1967).

[41] Holland, L., The Properties of Glass Surfaces (Chapman and Hall, London, 1964).

[42] Hass, G., and Thun, R. E., Editors, Physics of Thin Films (Academic Press, 1967).

(Paper 76A5-729) 